\title{
An acrylated isocyanonaphthalene based solvatochromic click reagent: Optical and biolabeling properties and quantum chemical modeling
}

\author{
Miklós Nagy ${ }^{\mathrm{a}}$, Dávid Rácz ${ }^{\mathrm{a}}$, Zsolt László Nagy ${ }^{\mathrm{a}}$, Tibor Nagy ${ }^{\mathrm{a}}$, Péter Pál Fehér ${ }^{\mathrm{b}}$, \\ Mihály Purgel ${ }^{\text {b, c }}$, Miklós Zsuga a , Sándor Kéki ${ }^{\text {a, * }}$ \\ a Department of Applied Chemistry, University of Debrecen, H-4032 Debrecen, Hungary \\ ${ }^{\mathrm{b}}$ Department of Physical Chemistry, University of Debrecen, H-4032 Debrecen, Hungary \\ ${ }^{c}$ MTA-DE Homogeneous Catalysis and Reaction Mechanisms Research Group, University of Debrecen, H-4032 Debrecen, Hungary
}

\section{A R T I C L E I N F O}

\section{Article history:}

Received 28 March 2016

Received in revised form 7 June 2016

Accepted 22 June 2016

Available online 23 June 2016

\section{Keywords:}

Fluorescence

Click reaction

Solvatochromism

Density-functional calculations

Bovine serum albumin

\begin{abstract}
A B S T R A C T
The optical and biolabeling properties of a novel molecule 1-(2-acryloyloxy-3-chloro-prop-1-yl)-amino5-isocyanonaphthalene (ACAIN) is reported. In addition to being a real solvatochromic fluorophore it reacts quantitatively and rapidly with simple thiols in a thiol-ene click reaction. DFT calculations revealed a dark nonfluorescent state of ACAIN due to a close energy triplet state where electron transition can happen between the acrylic double bond and the aromatic core through an intramolecular hydrogen bond between the $\mathrm{NH}$ and $\mathrm{C}=\mathrm{O}$ moieties. The hydrothiolation reaction is accompanied by a $1.5-19$ fold increase in fluorescence intensity depending on the solvent used owing to the saturation of the acrylic group. The quantum yield and reactivity of the molecules were found to be largely dependent on the substituent of the acryl moiety.

The biolabeling properties were investigated in detail by fluorometry and electrospray ionization (ESI)
\end{abstract} mass spectrometry using cysteine, KAC as a simple tripeptide and BSA as a model protein.

(c) 2016 Elsevier Ltd. All rights reserved.

\section{Introduction}

Over the past few decades, interest in the thiol-Michael addition reaction has increased dramatically, since it proceeds with high yield, stereoselectivity, rate, and is thermodynamically favored [1-4]. Thiol-ene additions can be extremely useful in the detection, localization, qualification and quantitation of intracellular thiols such as cysteine, glutathione or the free cysteine units of complex peptides [5]. The development of fluorescent probes that react through catalyzed (by base or nucleophile) Michael additions resulting in anti-Markovnikov addition products [6,7] has been in the focus in the last decades. The application of the reactive flourophore is more favorable when the base molecule in non/less fluorescent and the thiol addition is accompanied by a substantial increase in fluorescent intensity. Such fluorophores include pyrazolines [5] BODIPY [8], $\alpha, \beta$-unsaturated ketones [9] and nitroolefin-based coumarin [10].

\footnotetext{
* Corresponding author.

E-mail address: keki.sandor@science.unideb.hu (S. Kéki).
}

Solvatochromic dyes are important members of smart materials. The wavelength (color) and intensity of their emitted fluorescent light is affected by the environment, particularly by its polarity. This feature can be applied advantageously in molecular biology, especially as biolabeling dyes for fluorescence microscopy, where the different parts of biomolecules can be easily differentiated from each other by the various colors of the emitted fluorescent light caused by the polarity changes around the fluorophores. This phenomenon is also suitable for the determination of the structure of biomacromolecules (eg. peptides, or locate binding sites of enzymes), or even for following their interactions by observing the local changes [14].

Acryl(ate)s and methacryl(ate)s are easily reacted with thiols and can also be easily attached to different solvatochromic fluorophores. A good example is Acrylodan, a Prodan derivative bearing a reactive acryl moiety, which has a high affinity to thiols, therefore selectively labels proteins with free thiol groups $[15,16]$ and has many important applications in bioanalytics [17-20]. After reacting with the - $\mathrm{SH}$ group of biomolecules the conjugation of the acryloyl group with the close aromatic ring in Acrylodan will cease and 
fluorescence intensity increases dramatically. This phenomenon is useful in differentiating the unreacted dye from the labelled biomolecules and can be used in the construction of molecular switches. This intensity increase after the reaction does not necessarily require conjugation, it can also happen by the help of inter- or intramolecular H-bonding [21-24].

In addition to biolabeling, thiol-ene reactions can be preferable routes for the synthesis of various types of polymers, such as end functionalized polymers, dendrimers, furthermore several controlled radical polymerization techniques have also been developed based on this technique [11-13]. When a reactive fluorophore is used in the construction of smart networks, larger amounts are needed and consequently price and availability becomes serious issue. Most of these fluorophores are of complex structure or based on a pricey and hard to prepare backbone as is the case with Acrylodan. Therefore, there is a constant need for click reagents that are easily prepared from cheap and common starting materials using simple reactions, while the resulting fluorophore is solvatochromic, reacts completely with thiols, and has a dark and highly fluorescent state.

In this paper we report the design and preparation of a reactive solvatochromic dye (ACAIN) (and its methylated and chlorinated derivatives) by the modification of our recently developed molecule, 1-amino-5-isocyanonaphthalene (ICAN) [25] with only easily available reagents such as epichlorohydrin and acryloyl chloride. The acryl group reacts with thiols through a click reaction rapidly, followed by a significant increase of the emitted fluorescent light intensity because of the saturation of the double bond. ACAIN showed high affinity to thiol groups on a wide range of free thiolcontaining molecules without the use of any catalyst. The kinetics of its biolabeling properties were investigated in detail using cysteine, lysyl-alanyl-cysteine (KAC), and bovine serum albumin (BSA) by fluorometry and electrospray ionization (ESI) mass spectrometry. Based on density functional (DFT) calculations a model was developed for the description of the unique fluorescent behavior that can be useful in the development of fluorescent molecular switches. The resulting solvatochromic, highly fluorescent bioconjugate products can be particularly useful in pharmaceutical chemistry and fluorescence microscopy.

\section{Results and discussion}

The acryl group cannot be attached directly to the amino group of ICAN without disrupting its electron donating properties and as a consequence flawing the solvatochromic properties of the molecule. The attachment should be carried out using a spacer, favorably a short chain hydrocarbon. Epichlorohydrin offers an easy alternative because after the opening of the epoxy ring with the amine a secondary hydroxyl group is formed which in turn is easily reacted with acryloyl chloride as is presented in Scheme 1. The reaction was also carried out using methacryloyl-chloride and 2-choloroacrylic acid to investigate the change in the optical properties when an electron donating $(\mathrm{Me})$ and an electron withdrawing $(\mathrm{Cl})$ group is present on the acryl moiety.

To test the solvatochromic properties of ACAIN and its derivatives $\mathrm{UV}-\mathrm{Vis}$ and steady-state fluorescence measurements were carried out. It should be noted, however, that this paper focuses on ACAIN, therefore its properties are presented in the main article, while the corresponding data for MACAIN and CACAIN are presented in the supporting information.

The UV-Vis spectrum of ACAIN recorded in THF shows a diffuse band between $\lambda=300 \mathrm{~nm}$ and $400 \mathrm{~nm}$ with a peak value of $366 \mathrm{~nm}$ (spectrum No. 1. in Fig. 1).

The peak position showed only a slight variation between $\lambda_{\max }=356-373 \mathrm{~nm}$ depending on the solvent used. The extinction coefficient corresponding to this peak varies between $\varepsilon=5700 \mathrm{M}^{-1} \mathrm{~cm}^{-1}$ in water and $\varepsilon=9100 \mathrm{M}^{-1} \mathrm{~cm}^{-1}$ in dichloromethane. The double peak structure of the band is characteristic for the ICAN derivatives containing free $\mathrm{NH}$-hydrogen [33] and is most probably due to the superposition of the $\mathrm{NH}$ bending vibrational transition onto the absorption spectrum. It should be noted that the experimental UV-Vis spectra are in very good agreement with the calculated spectra (Fig. S22 in the Supporting Information (SI)). Emission spectra were recorded in solvents of different polarity. The results are summarized in Table 1 for ACAIN and for MACAIN and CACAIN in TableS1(a)-S1(b) in the SI.

As can be seen from the data of Table 1. ACAIN has visible emission in every solvent investigated. Characteristically for solvatochromic behavior the Stokes shifts increase with solvent polarity, that is bathochromic shift of the emitted light with increasing solvent polarity was found. The lowest emission wavelength was observed in hexane with $\lambda_{\mathrm{em}, \max }=423 \mathrm{~nm}$, the largest in water $\lambda_{\mathrm{em}, \max }=502 \mathrm{~nm}$ and that of the THF solution can be found in between them at $\lambda_{\mathrm{em}, \max }=460 \mathrm{~nm}$ as is presented in Fig. 1 . Surprisingly low quantum yields were observed in nonpolar solvents for all three compounds compared to the values of the starting ICAN molecule, which has the strongest emission in such solvents. According to the data of Table S1 the introduction of an electron donating methyl group to the 2 position of the acryl moiety of ACAIN increases the quantum yields in almost every solvent by $\sim 10-20 \%$. On the other hand, the introduction of the electron withdrawing chlorine atom to the same position drastically lowers the QY values, that is the QYs do not exceed $10 \%$ even in polar solvents in the case of CACAIN. The explanation for these phenomena will be presented later.

The solvent-dependent behavior of ACAIN was quantitatively described by the most recent Catalán model [44] according to Equation (1).

$Y=Y_{o}+a S A+b S B+s S P+t S d P$,

where $Y_{0}$ is the property of the substance of interest (e.g., emission maximum and Stokes shift) in the absence of solvent, for example, in the gas phase. SA is the quantitative empirical measure of the ability of bulk solvent to act as a hydrogen-bond donor towards a solute. SB is the quantitative empirical measure of the ability of a bulk solvent to act as a hydrogen-bond acceptor or electron-pair donor towards a solute, forming a solute-to-solvent hydrogen bond or a solvent-to-solute coordinative bond, respectively. SP and SdP are the solvent polarizability and dipolarity parameters, respectively, determined using reference dye molecules. $a, b, s$ and $t$ are the corresponding coefficients and their inclusion in the equation indicates the dependence of the property under investigation upon the respective solvent parameter.

The Catalán coefficients for the emission wavenumber at the maximum $\left(\bar{\nu}_{\text {em,max }}\right)$ and the Stokes shifts $(\Delta \bar{\nu})$ were obtained by multilinear regression analysis and are summarized in Table 2 . The corresponding SA, SB, SP and SdP values of the solvents along with the plots of the measured values of $\bar{\nu}_{\mathrm{em} \text {,max }}$ and $\Delta \bar{\nu}$ versus their calculated values according to Eq. (1) for ACAIN (and its derivatives) are presented in the Supporting Information as Table S4 and Fig. S9. According to the data ACAIN, MACAIN and CACAIN can be considered as real solvatochromic dyes.

As seen from the data of Table 2 solvent polarity has the largest effect on the solvatochromic behavior but both the H-bond donating and accepting capabilities of ACAIN are also pronounced (large $\mathrm{a}$ and $\mathrm{b}$ parameters) because of the presence of the free $\mathrm{NH}$ hydrogen (H-bond donor) and the isonitrile group (H-bond acceptor). 
<smiles>Nc1cccc2c(N=O)cccc12</smiles>

1. ICAN

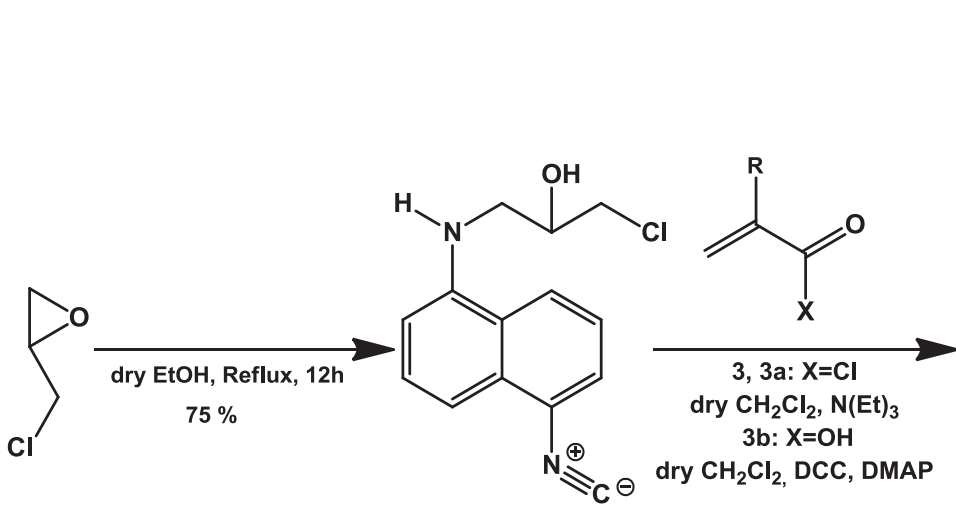

2. CHAIN<smiles>[R]C(=C)C(=O)OC(CCl)CNc1cccc2c(N=[O+])cccc12</smiles>

3. $\mathrm{R}=\mathrm{H}$, ACAIN
3a. $\mathrm{R}=\mathrm{Me}$, MACAIN
3b. $\mathrm{R}=\mathrm{CI}$, CACAIN

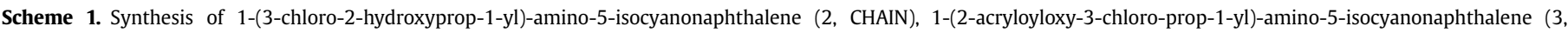

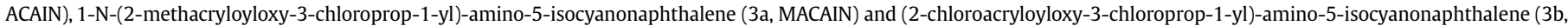
CACAIN).

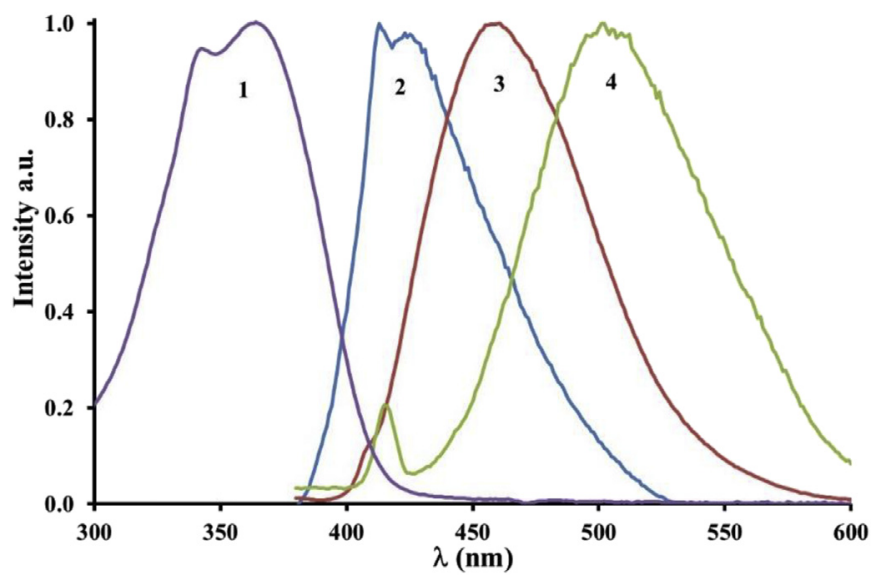

Fig. 1. The normalized absorption (1) and emission spectra of ACAIN recorded in hexane (2), THF (3) and water (4). The absorption spectrum was recorded in THF. thiols via a Michael addition mechanism. This click type hydrothiolation reaction is well documented [7] and has many practical applications such as protein labeling using the free $\mathrm{SH}$ group of the cysteine moiety.

The reactivity of ACAIN in thiol-ene click reactions was studied using a variety of thiols starting from simple aliphatic (propanethiol) and aromatic (thiophenol) ones through simple biomolecules such as cysteine, peracetyl- $\alpha$-thioglucose and lysyl-alanyl-cysteine (KAC), a tripeptide, to proteins such as bovine serum albumin (BSA). The reactions were followed by ${ }^{1} \mathrm{H}$ NMR or ESI MS methods. The reaction conditions are summarized in Table 3 except for $\mathbf{8}$ and $\mathbf{9}$ which will be dealt in detail later.

A number of solvents were examined but acceptable conversion was observed only in DMSO and water. The hydrothiolation reaction of the acryl group usually requires an amine catalyst such as triethylamine (TEA). However, in the case of propanethiol and thiophenol an almost instantaneous reaction was observed in $\mathrm{d}_{6^{-}}$ DMSO at room temperature after the addition of the thiols in two-

Table 1

Excitation $\left(\lambda_{\mathrm{ex}}\right)$, emission $\left(\lambda_{\mathrm{em}}\right)$ maxima, Stokes shift $(\Delta v)$, molar absorbance $(\varepsilon)$ and quantum yield $\left(\Phi_{\mathrm{F}}\right)$ of ACAIN in different solvents.

\begin{tabular}{|c|c|c|c|c|c|}
\hline Solvent & $\lambda_{\text {ex }}(n m)$ & $\lambda_{\text {em }}(n m)$ & Stokes shift $\left(\mathrm{cm}^{-1}\right)$ & $\varepsilon\left(\mathrm{M}^{-1} \mathrm{~cm}^{-1}\right)$ & $\Phi_{\mathrm{F}}(\%)$ \\
\hline Hexane & 356 & 423 & 4449 & 8500 & 3 \\
\hline Cyclohexane & 359 & 423 & 4214 & 7040 & 8 \\
\hline Toluene & 362 & 439 & 4845 & 8100 & 5 \\
\hline Dichloromethane & 362 & 456 & 5694 & 9100 & 7 \\
\hline i-Propanol & 367 & 477 & 6284 & 6450 & 26 \\
\hline Tetrahydrofuran & 366 & 460 & 5583 & 7950 & 18 \\
\hline Chloroform & 363 & 455 & 5570 & 7200 & 10 \\
\hline Ethyl acetate & 366 & 459 & 5536 & 8000 & 19 \\
\hline Dioxane & 364 & 456 & 5543 & 7640 & 15 \\
\hline Acetone & 368 & 472 & 5987 & 6800 & 35 \\
\hline Methanol & 367 & 485 & 6629 & 7740 & 18 \\
\hline Acetonitrile & 364 & 479 & 6596 & 7500 & 25 \\
\hline Pyridine & 369 & 479 & 6223 & 7110 & 9 \\
\hline Dimethyl formamide & 370 & 482 & 6280 & 7280 & 46 \\
\hline Dimethyl sulfoxide & 373 & 490 & 6401 & 6800 & 63 \\
\hline Water & 362 & 502 & 7704 & 5700 & 3 \\
\hline
\end{tabular}

\subsection{Reaction of ACAIN with thiols}

Acrylates, like many activated olefins are easily reacted with fold molar amount relative to ACAIN. As can be seen in the ${ }^{1} \mathrm{H}$ NMR spectra presented in Fig. 2 after 5 min reaction time the olefin proton signals of the acryl group completely disappeared. The 
Table 2

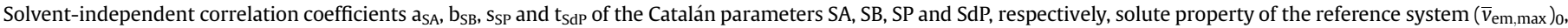
correlation coefficient $(\mathrm{r})$ and number of solvents $(\mathrm{n})$ calculated by multiregression analysis for the solvatochromism of CHAIN and ACAIN.

\begin{tabular}{|c|c|c|c|c|c|c|c|}
\hline \multirow[t]{2}{*}{ Compound } & $\bar{\nu}_{\mathrm{em}, \mathrm{max}, 0}$ & $a_{S A}$ & $\mathrm{~b}_{\mathrm{SB}}$ & $\mathrm{s}_{\mathrm{SP}}$ & $\mathrm{t}_{\mathrm{SdP}}$ & \multirow[t]{2}{*}{$\mathrm{r}$} & \multirow[t]{2}{*}{$\mathrm{n}$} \\
\hline & $\left(\mathrm{cm}^{-1}\right)$ & & & & & & \\
\hline CHAIN & $29300 \pm 1139$ & $-2715 \pm 480$ & $-2746 \pm 588$ & $-5918 \pm 1384$ & $-2675 \pm 1064$ & 0.968 & 14 \\
\hline ACAIN & $29113 \pm 1252$ & $-2349 \pm 635$ & $-2037 \pm 775$ & $-5356 \pm 1714$ & $-3062 \pm 1376$ & 0.947 & 15 \\
\hline
\end{tabular}

Table 3

The reaction conditions of the hydrothiolation reaction of ACAIN with different thiols. The conversion values are given for ACAIN and all reactions were carried out at $25{ }^{\circ} \mathrm{C}$.

\begin{tabular}{llllll}
\hline Thiol no. & [Thiol] & {$[$ ACAIN] } & Solvent & Time & Conversion \\
\hline $\mathbf{4}$ & $0.106 \mathrm{M}$ & $0.053 \mathrm{M}$ & $\mathrm{d}_{6}$-DMSO & $<5 \mathrm{~min}$ & $100 \%$ \\
$\mathbf{5}$ & $0.318 \mathrm{M}$ & $0.159 \mathrm{M}$ & $\mathrm{d}_{6}$-DMSO & $<5 \mathrm{~min}$ & $100 \%$ \\
$\mathbf{6}$ & $0.079 \mathrm{M}$ & $0.053 \mathrm{M}$ & $\mathrm{d}_{6}$-DMSO: $\mathrm{D}_{2} \mathrm{O}(1: 1)$ & $<5 \mathrm{~min}$ & $100 \%$ \\
$\mathbf{7}$ & $0.190 \mathrm{M}$ & $0.095 \mathrm{M}$ & DMSO & $1 \mathrm{~h}$ & $46 \%$ \\
\hline
\end{tabular}

compiled in Table 4. The most dramatic increase in fluorescence intensity was observed in the less polar solvents hexane, toluene and dichloromethane where the increase was 13-19 fold, while in the most polar solvents except water it was only $1.5-2.5$ fold. The emission maxima and the shape of the emission peak were virtually unchanged. The extinction coefficients of the thiol adducts were also found to be very close to those of ACAIN within a 10\% error. Based on these observations it is surmised that the acryl group gives rise to a non-radiative path from the excited state to the

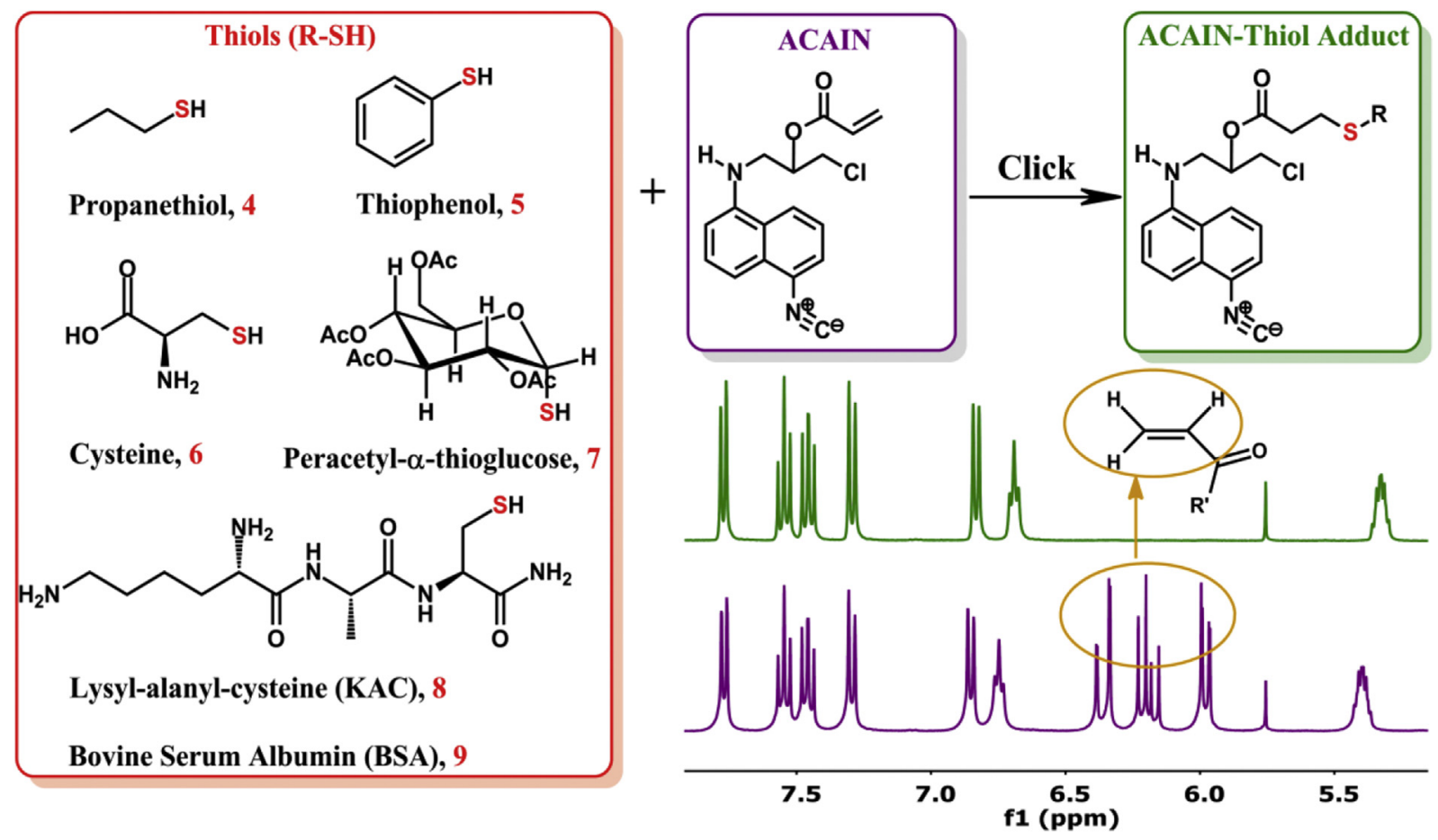

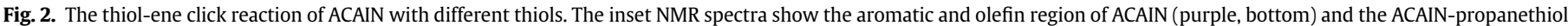
reaction mixture after $5 \mathrm{~min}$ (green, top). (For interpretation of the references to colour in this figure legend, the reader is referred to the web version of this article.)

formation of the addition product was confirmed by ESI-MS measurements and by the appearance of the $\mathrm{S}-\mathrm{CH}_{2}$ signals at 2.62 and $2.41 \mathrm{ppm}$. It can also be seen from the ${ }^{1} \mathrm{H}$ NMR spectra that the thiol addition does not affect the electronic structure of the naphthalene core, only the signal of the $\mathrm{NH}$ proton shifts slightly downfield from 5.39 to $5.33 \mathrm{ppm}$.

Unlike the ${ }^{1} \mathrm{H}$ NMR spectrum, the adduct formation largely affects the fluorescence behavior of ACAIN. It was noted earlier that ACAIN has low quantum yields especially in nonpolar solvents. In contrast, the ACAIN-propanethiol adduct showed intense fluorescence in almost all solvents as can be seen in Fig. 3. This intensity increase was not limited to the ACAIN-propanethiol adduct but could be observed in the case of every other thiols $(\mathbf{5}, \mathbf{6}, \mathbf{7}, \mathbf{8}, \mathbf{9})$, as well.

The fluorescence properties of ACAIN and its PrSH adduct are ground state. By saturating the double bond this non-radiative way is eliminated and the quantum efficiencies increase considerably. The explanation of this phenomenon will be given in the quantum chemical part of the paper.

The reactivity of MACAIN and CACAIN was also investigated in the presence of propanethiol. Using the same experimental conditions as with ACAIN no reaction of PrSH with MACAIN could be observed, while CACAIN reacted approximately 100 times faster than ACAIN in DMSO as is presented in Fig. S10. Unfortunately the increased reactivity of CACAIN is accompanied by lower hydrolytic stability, namely CACAIN was found to hydrolyze in water even at $\mathrm{pH}=7$. It should be noted, however, that no significant hydrolysis could be detected in the case of ACAIN in aqueous buffers applied during the kinetic measurements at $\mathrm{pH}=7, \mathrm{pH}=8$ and $\mathrm{pH}=9$. In addition, ACAIN has very low quantum yield in water, a common 

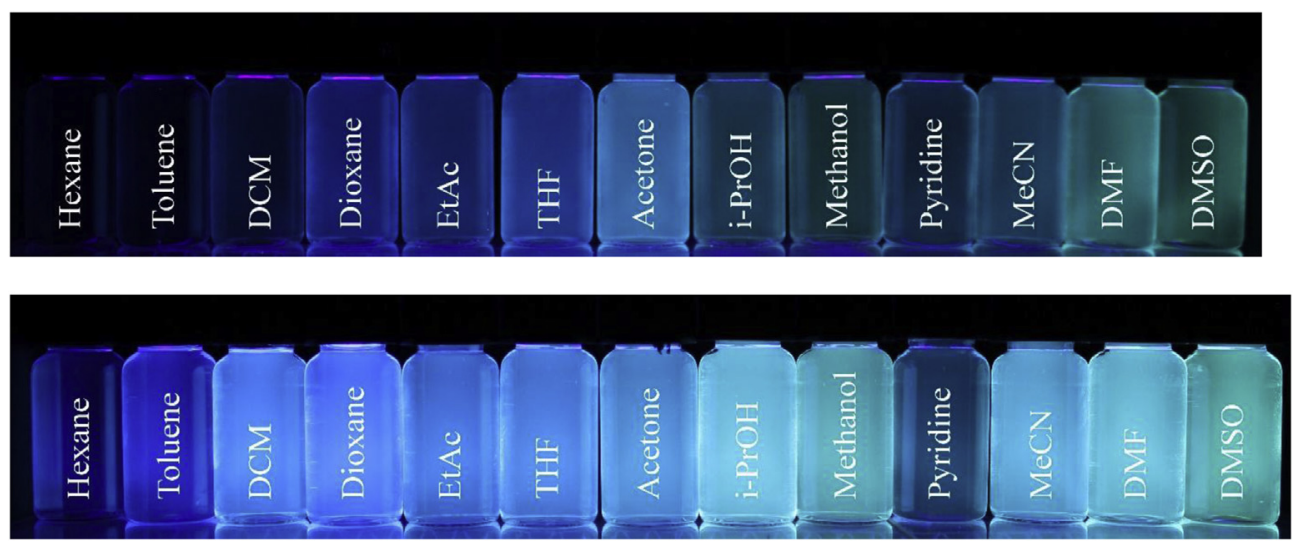

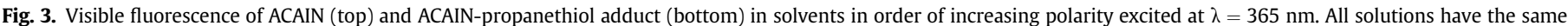
concentration: $25.4 \mu \mathrm{M}$.

Table 4

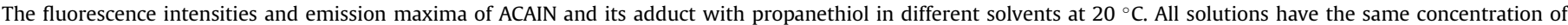
$2.54 \mu \mathrm{M}$. The intensity ratios were calculated relative to the intensities of the pure ACAIN solutions.

\begin{tabular}{|c|c|c|c|c|c|}
\hline \multirow[t]{2}{*}{ Solvent } & \multicolumn{2}{|c|}{ Pl. Intensity } & \multicolumn{2}{|c|}{$\lambda_{(\mathrm{em})} \mathrm{nm}$} & \multirow[t]{2}{*}{ Intensity ratio } \\
\hline & ACAIN & ACAIN + PrSH & ACAIN & ACAIN + PrSH & \\
\hline Hexane & 189 & 2836 & 423 & 424 & 15.0 \\
\hline Toluene & 160 & 3011 & 439 & 438 & 18.8 \\
\hline Dichloromethane & 237 & 3210 & 456 & 457 & 13.5 \\
\hline i-Propanol & 838 & 3226 & 477 & 481 & 3.8 \\
\hline Tetrahydrofuran & 760 & 2831 & 460 & 458 & 3.7 \\
\hline Ethyl-acetate & 713 & 2808 & 459 & 460 & 3.9 \\
\hline Dioxane & 648 & 3824 & 456 & 450 & 5.9 \\
\hline Acetone & 1277 & 2536 & 472 & 470 & 2.0 \\
\hline Methanol & 674 & 2268 & 485 & 485 & 3.4 \\
\hline Pyridine & 634 & 932 & 479 & 479 & 1.5 \\
\hline Acetonitrile & 1132 & 2598 & 479 & 480 & 2.3 \\
\hline Dimethyl formamide & 2183 & 3352 & 482 & 484 & 1.5 \\
\hline Dimethyl sulfoxide & 1977 & 3241 & 490 & 490 & 1.6 \\
\hline Water & 85 & 305 & 502 & 494 & 3.6 \\
\hline
\end{tabular}

feature among many solvatochromic fluorophores. In polar protic solvents such as water the energy gap that separates the $S_{0}$ and $S_{1}$ states is reduced leading to a marked increase in non-radiative decay and results in a decrease in the fluorescence quantum yield [14]. The low quantum yield may be favorable in applications such as biolabeling.

\subsection{Kinetic investigation of the reaction of ACAIN with biomolecules}

The reaction between ACAIN and different compounds containing thiol $(-\mathrm{SH})$ groups were followed spectrofluorometrically. The fluorescence intensity versus time curves for the reaction of ACAIN with cysteine, KAC and BSA at different $\mathrm{pH}$ are shown in Fig. 4.

As seen in Fig. 4 the fluorescence intensities increase with time constantly until plateau values have been reached indicating the completion of the reaction, i.e., covalent binding of all ACAIN molecules to the target compounds through acryl-thiol reaction. Moreover, in the case of BSA as can be seen in Fig. 4 c., there are large increases in the fluorescence intensity at the very beginning of the reaction followed by much slower increases in the fluorescence intensities. The initial, very sharp and large increase in the fluorescence intensities, which occur instantly upon adding of BSA to the ACAIN solution, can be ascribed to the fast non-covalent binding of ACAIN molecules to the BSA as was previously demonstrated for Acrylodan and BSA by Mims et al. [16]. ACAIN itself reveals poor fluorescence in water due to the low quantum yield but becomes brightly fluorescent on non-covalent binding to BSA ascribed to the change of the micro-environment of ACAIN molecules. The change of the environment of ACAIN molecules results in a considerable increase in quantum yield and blue shifted emission maximum from $502 \mathrm{~nm}$ to $462 \mathrm{~nm}$. The further, relatively slow increase in the fluorescence intensities are due to the covalent binding of ACAIN molecules to the BSA via acryl-thiol reaction involving the free thiol group of Cys-34 unit of BSA. It should be noted, that the second slow increase in fluorescence intensity was completely missing when the experiment was repeated using $\mathbf{1}$ as the fluorophore (Fig. S11 in the SI).

To evaluate the kinetic curves presented in Fig. 4., we can assume a second-order kinetics for the reaction of the fluorophore (F) with the substrate (S) according to eq. (2).

$F+S \rightarrow F S$

In these kinetic experiments large excess of molar concentrations of $\mathrm{S}$ to those of $\mathrm{F}$ were applied, i.e., $[\mathrm{S}]_{0} \gg[\mathrm{F}]_{0}$, to obtain pseudo first-order kinetics. Using the pseudo first-order kinetics eq. (3) can be derived for the variation of the fluorescence intensity with time (the derivation of eq. (3) can be found in the Supporting Information) 

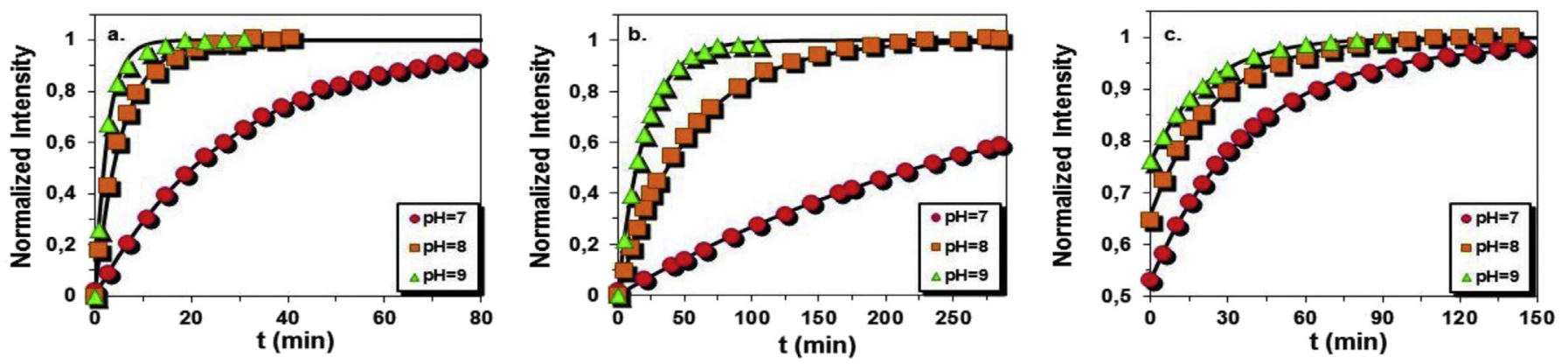

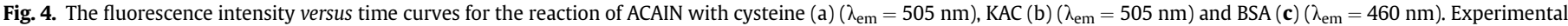

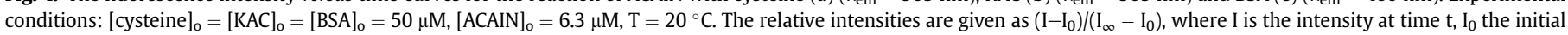
and $\mathrm{I}_{\infty}$ the final fluorescence intensity.

$I(t)=I_{O}+\Delta I\left(1-e^{-k_{o b s} t}\right)$

where $\Delta I=I_{\infty}-I_{0}$, and $\mathrm{I}_{\mathrm{o}}$ and $\mathrm{I}_{\infty}$ are the initial and final fluorescence intensities, respectively.

Eq. (3). was fitted to the experimental fluorescence intensity versus time curves to determine the values of $\mathrm{k}_{\mathrm{obs}}$. According to the results, $\mathrm{k}_{\mathrm{obs}}$ values increased with the $\mathrm{pH}$, suggesting that the deprotonation of the thiol group play an important role in the rate determining step of the acryl-thiol reaction. Assuming that the thiolate anion reacts much faster with the acryl group of ACAIN than the undissociated thiol group, eq. (4) can be applied (the derivation of eq. (4). is shown in the Supporting Information)

$\frac{1}{k_{\text {obs }}}=\frac{1}{k_{\text {thiolate }} K_{a}[S]_{o}}\left[H^{+}\right]+\frac{1}{k_{\text {thiolate }}[S]_{o}}$

where $\mathrm{k}_{\text {thiolate }}$ and $\mathrm{K}_{\mathrm{a}}$ are rate constants for thiolate-acryl reaction and the acid dissociation constant of the thiol group.

Plotting $1 / \mathrm{k}_{\mathrm{obs}}$ as a function of $\left[\mathrm{H}^{+}\right]$yielded straight lines (see Supporting Information Fig. S12). From the slopes and intercepts of these lines, the values of $\mathrm{K}_{\mathrm{a}}$ were obtained. The $\mathrm{pK}_{\mathrm{a}}$ values determined for cysteine and KAC using eq. (4). are 8.1 and 8.2, respectively. It is important to note that these values are very close to the literature values of $\mathrm{pK}_{\mathrm{a}}$ reported for the free cysteine that are in the range of 8.2-8.5 [26,27]. However, the $\mathrm{pK}_{\mathrm{a}}$ value determined for the BSA is $\sim$, which is lower than those obtained for cysteine and KAC. This result, however, seems to be in line with the reported $\mathrm{pK}_{\mathrm{a}}$ values for BSA being in the range of $7-8.5[28,29]$.

It is known that the acryl moiety is not only electrophilic towards sulfhydryl groups but can also react with amines. Therefore, acryl containing fluorophores such as Acrylodan can also modify lysine residues during the biolabeling of proteins [16,30]. Our model protein BSA contains $\mathbf{3 5}$ cysteines and $\mathbf{5 8}$ lysines [31,32]; however, all of the cysteine residues, with the exception of Cys-34, are involved in intramolecular disulfide bonds. The lysine/free cysteine ratio is 58 to 1 in BSA, therefore for practical applications it is important to determine the selectivity of ACAIN towards free cysteine units. Mass spectrometric methods such as ESI-MS and MS/MS provide an efficient way to study not only the kinetics but also the binding point of ACAIN during the labeling reaction therefore MS studies were also carried out to get deeper insight into the reaction of ACAIN with KAC and BSA. For these experiments unbuffered solutions were applied in order to avoid using of buffers incompatible with ESI and ion suppression. To investigate the selectivity of ACAIN with $\mathrm{SH}$ and $\mathrm{NH}_{2}$ groups it was reacted with a simple tripeptide, KAC where an N-terminal lysine $(\mathrm{K})$ is separated by an alanine (A) from a C-terminal cysteine (C) with amide functionality. KAC therefore contains $2 \mathrm{NH}_{2}$ (lysine) and $1 \mathrm{SH}$ (cysteine) group. ACAIN (1.04 mM) was mixed with KAC (0.52 mM) in water/DMSO $(50 / 50 \mathrm{~V} / \mathrm{V})$ at $25^{\circ} \mathrm{C}$. Samples were taken out at predetermined times, up to $6 \mathrm{~h}$ reaction time, and were analyzed by ESI-MS/MS method.

Similar fragmentation pathway was found for the KAC and the labelled KAC, which shows that the connected ACAIN has no significant effect on the fragmentation pattern.

Fig. 5 shows the ESI-MS/MS spectrum of the ACAIN-KAC adduct recorded after 6 h reaction time.

As can be seen in Fig. 5 the presence of the ACAIN-KAC adduct is supported by the accurate mass of the protonated adduct ion, [ACAIN-KAC $+\mathrm{H}^{+}$with $m / z 634.256$ (634.257 calculated) and the fragmentation pattern. The majority of the product ions come from the fragmentation of the tripeptide backbone. Based on the tandem mass spectrum the ACAIN binding point can be determined by the analysis of the product ions. The fragment ions generated in the higher mass region are produced by the loss of the lysine and the alanine. These amino acids appear in the mass spectrum as the $\mathbf{a}_{1}$, $\mathbf{a}_{1}{ }^{*}, \mathbf{a}_{2}, \mathbf{b}_{1}, \mathbf{b}_{2}$ and $\mathbf{b}_{2}{ }^{*}$ type product ions. According to the ESI-MS spectrum, neither cysteine, nor any product ion containing cysteine with free thiol group can be detected, while all of the fragment ions which contain cysteine are labelled with ACAIN. Furthermore, no lysine bound to ACAIN can be detected, while the $\mathbf{x}, \mathbf{y}$ and $\mathbf{z}$ type fragment ions can only be found with the ACAIN moiety. It should be noted that these $\mathbf{x}, \mathbf{y}$ and $\mathbf{z}$ type fragment ions appeared in the tandem mass spectrum of unlabelled KAC. The ESIMS/MS spectrum of the unlabelled KAC tripeptide can be found in the supporting information as Fig. S13. Based on the MS/MS investigations, it can be concluded that the ACAIN reacts only with the cysteine moiety of the KAC tripeptide and no reaction with the amine groups under the applied reaction conditions could be observed.

The ESI MS investigation of the labeling of BSA with ACAIN using the same experimental conditions as in the case of KAC followed. Attachment of one ACAIN molecule to a BSA molecule increases the mass of BSA with 315 Da compared to that of the starting protein. According to Fig. 6., the BSA-ACAIN reaction can be followed by ESIMS method. At $\mathrm{t}=0 \mathrm{~min}$ the typical mass spectrum of the protonated starting protein at different charge states can be observed. The measured masses and the charges of the ions are marked over the peaks. After 40 min reaction time another series of peaks is clearly visible in the middle panel of Fig. 6, which belongs to the BSA-ACAIN reaction product. The charge state of these ions is the same as that of the corresponding BSA ions. In order to gain the masses of the compounds deconvolution was used (Fig. S14 in the Supporting Information). As it can be seen the differences between the masses of labelled and unlabelled BSA is $315 \mathrm{Da}$, which is in very 


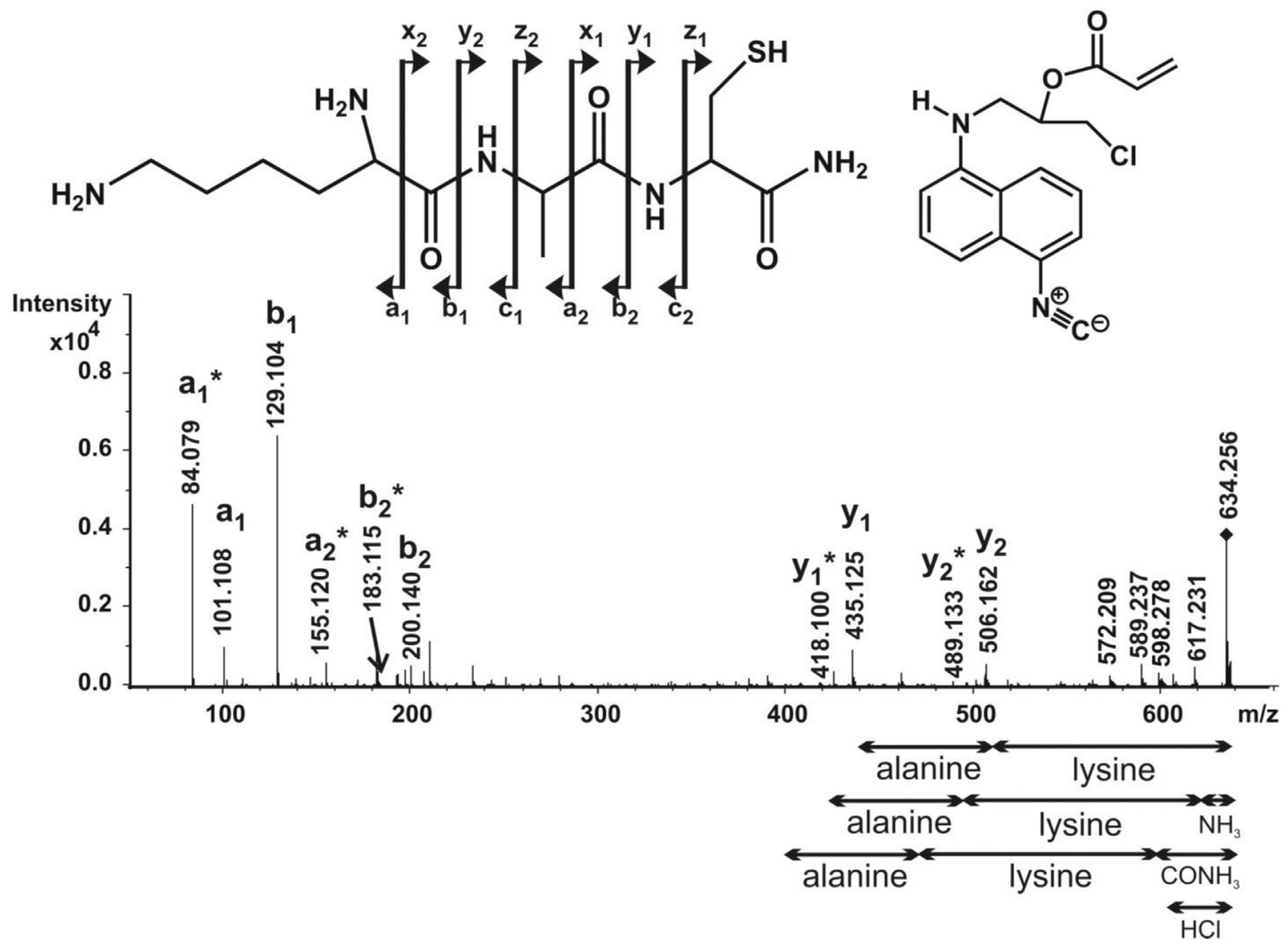

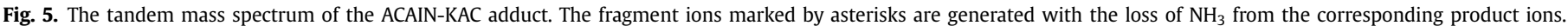
Figure inset shows the structures of the ACAIN and the KAC and the possible generated fragment ions of the KAC molecule.

good agreement with the mass of the ACAIN molecule (315 Da). However, after 260 min reaction time a third series with a molecular weight of 630 Da higher appeared which belongs to the BSA2ACAIN adducts. Although it was shown that ACAIN does not bind to the lysine moiety of KAC it reacts with one lysine of BSA. This behavior was previously shown in the reaction of Acrylodan with BSA [16] and with Interleukin-1 $\beta$ [30]. Since ACAIN is a hydrophobic molecule just as Acrylodan, it tends to incorporate into the hydrophobic pockets of proteins. BSA has two such hydrophobic pockets: one at Cys-34 where the first ACAIN molecule binds and the other at Lys-240 where the lysine moiety is activated because of its nonpolar environment and the second ACAIN binding most likely happens. The assumption that ACAIN binds to the only activated lysine (Lys240) of BSA is further supported by the fact that no additional series appeared in the mass spectrum, no matter how long the reaction was allowed to proceed.

Further details including the kinetic curves for the reactions of ACAIN with KAC and BSA are presented in the Supporting Information as Figs. S15 and S16, respectively.

\subsection{DFT calculations}

For practical applications and for the design of more effective fluorophores it is important to know why and how the ACAIN molecule has negligible fluorescence in the least polar and observable emission in the most polar solvents. Therefore, we selected hexane and DMSO as model solvents and calculated the ground state $\left(\mathrm{S}_{0}\right)$ and excited state $\left(\mathrm{S}_{1}\right.$ and $\left.\mathrm{T}_{1}\right)$ geometries with the electronic spectra of ACAIN and its thiol adduct. The DMSO system was expanded with an explicit solvent molecule to account for the $\mathrm{H}$-bonding between the ACAIN and the DMSO. Our focus was mainly on the role of the acryl group.

Depending on the polarity of the solvent molecules, intramolecular or solvent-solute interactions can dominate which give rise to different molecular structures in different solvents. The calculated equilibrium structures of ACAIN in n-hexane at different electronic states are shown in Fig. S17 in the Supporting Information. All the structures have an intramolecular $\mathrm{H}$-bond between the amino group and the acrylic oxygen. Also, in the $\mathrm{S}_{1}$ and $\mathrm{T}_{1}(\mathrm{O})$ states the acryl group becomes almost coplanar with the naphthalene ring. We found that in the triplet state a hydrogen atom (or proton) transfer from the $\mathrm{NH}$ group $\left(\mathrm{T}_{1}(\mathrm{~N})\right)$ to the acrylic oxygen is possible $\left(\mathrm{T}_{1}(\mathrm{O})\right)$ but the $\mathrm{T}_{1}(\mathrm{~N})$ state is lower in energy. Moreover at the ground and $\mathrm{S}_{1}$ states we found no local minima with O-localized proton which means that no excited-state intramolecular protontransfer (ESIPT) will occur on the $S_{1}$ surface.

On the other hand these geometry optimizations revealed a possibility for the lack of emission because of intersystem crossing (ISC) which is most likely to happen between $S_{1}$ and $T_{1}(O)$ as they are similar in geometry and very close in energy $(5.4 \mathrm{~kJ} / \mathrm{mol})$ making the overlap of their vibrational energy levels possible. The energy diagram in Fig. 7 shows the electronic energy of the ground, $\mathrm{S}_{1}$ and $\mathrm{T}_{1}$ electronic states in the $\mathrm{S}_{1}$ optimized geometry along with the energy minimum of the $\mathrm{T}_{1}(\mathrm{~N})$ and $\mathrm{T}_{1}(\mathrm{O})$ states. The dashed and dotted lines show approximations of the potential energy surfaces. It can be seen, however, that the energies of $S_{1}$ and $T_{1}(O)$ are close 


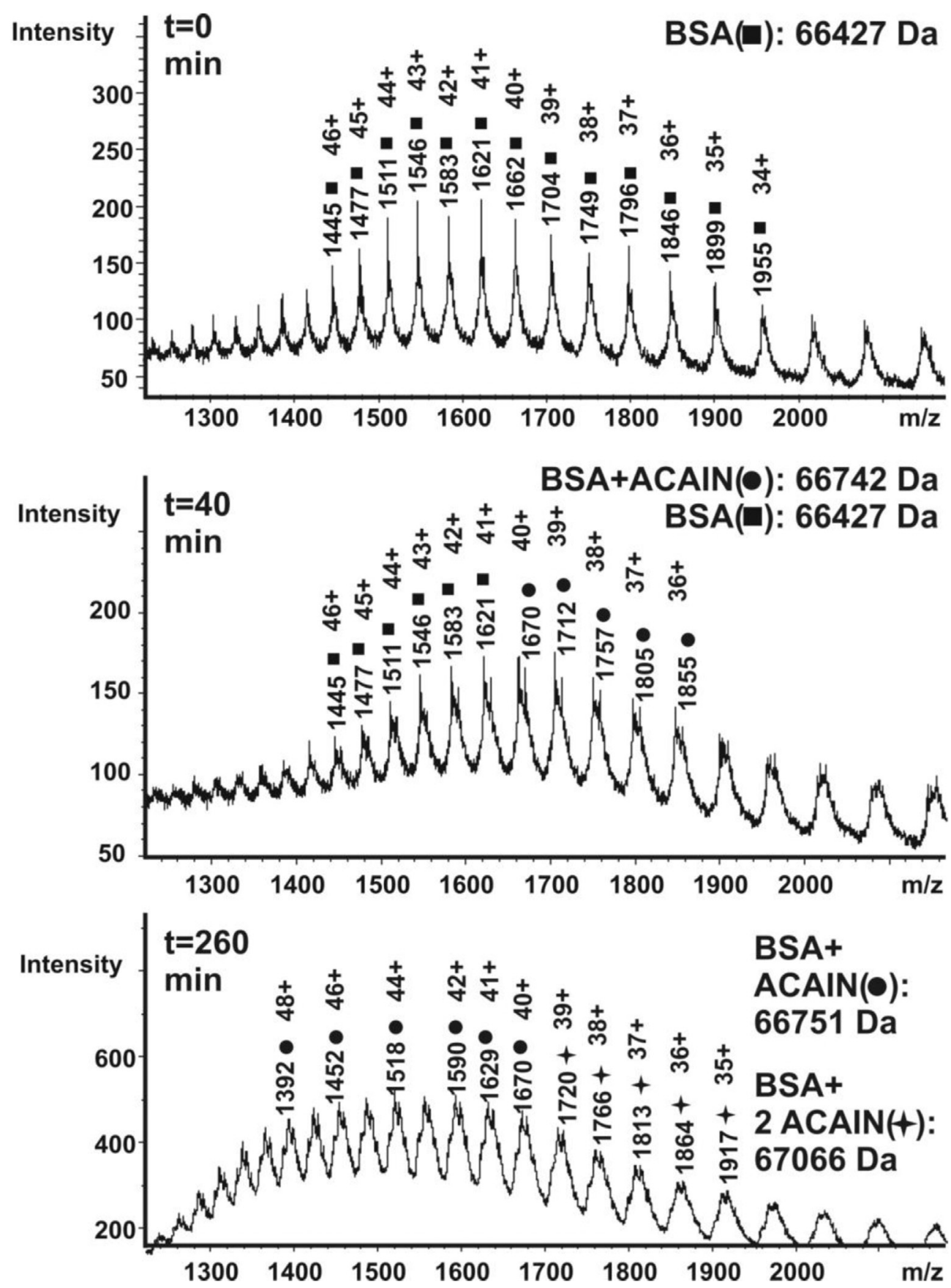

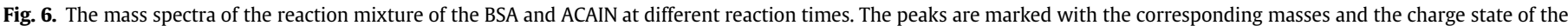
ions. Experimental conditions: $[\mathrm{BSA}]_{\mathrm{o}}=0.52 \mathrm{mM},[\mathrm{ACAIN}]_{\mathrm{o}}=1.04 \mathrm{mM}$ in water/DMSO $(50 / 50 \mathrm{~V} / \mathrm{V})$ at $25^{\circ} \mathrm{C}$.

to each other and the conical intersection point for the relaxation into the $T_{1}(\mathrm{~N})$ state lies even closer to $\mathrm{S}_{1}$.

For the thiol adduct although the energy difference between the $\mathrm{S}_{1}$ and $\mathrm{T}_{1}(\mathrm{O})$ is also relatively small $(12.0 \mathrm{~kJ} / \mathrm{mol})$ ISC cannot happen because the geometry of $S_{1}$ is much closer to the other triplet minimum $\left(\mathrm{T}_{1}(\mathrm{~N})\right)$ with an energy separation of $78.7 \mathrm{~kJ} / \mathrm{mol}$. Furthermore, the $\mathrm{T}_{1}(\mathrm{O})$ state is much higher in energy than the other two states in Fig. S19.

The situation in DMSO is different as there is an H-bond between the amino group and a DMSO molecule, while the acryl unit is $\pi$-stacked to the naphthalene ring (Fig. S18). The structures of $\mathrm{S}_{0}$, $\mathrm{S}_{1}$ and $\mathrm{T}_{1}(\mathrm{~N})$ are very similar to each other, while in the $\mathrm{T}_{1}(\mathrm{O})$ state the hydrogen favors the acrylic oxygen over the DMSO and upon protonation the acryl unit twists out from the $\pi$-stacking. This is similar to what was observed in the case of the thiol adduct in hexane because the energy spacing of the $S_{1}$ and $T_{1}(0)$ states is also small $(8.6 \mathrm{~kJ} / \mathrm{mol})$. Moreover, they are still far away on the potential energy surface due to their geometries. The energy difference between the similar structures of $\mathrm{S}_{1}$ and $\mathrm{T}_{1}(\mathrm{~N})$ is $56.2 \mathrm{~kJ} / \mathrm{mol}$ (Fig. S20) which is about ten times higher than the one calculated in hexane. Therefore, the non-radiative relaxation to the $T_{1}$ state in DMSO is less probable than in hexane.

The calculated electronic spectra are in good agreement with the experimental results except for the emission of ACAIN 


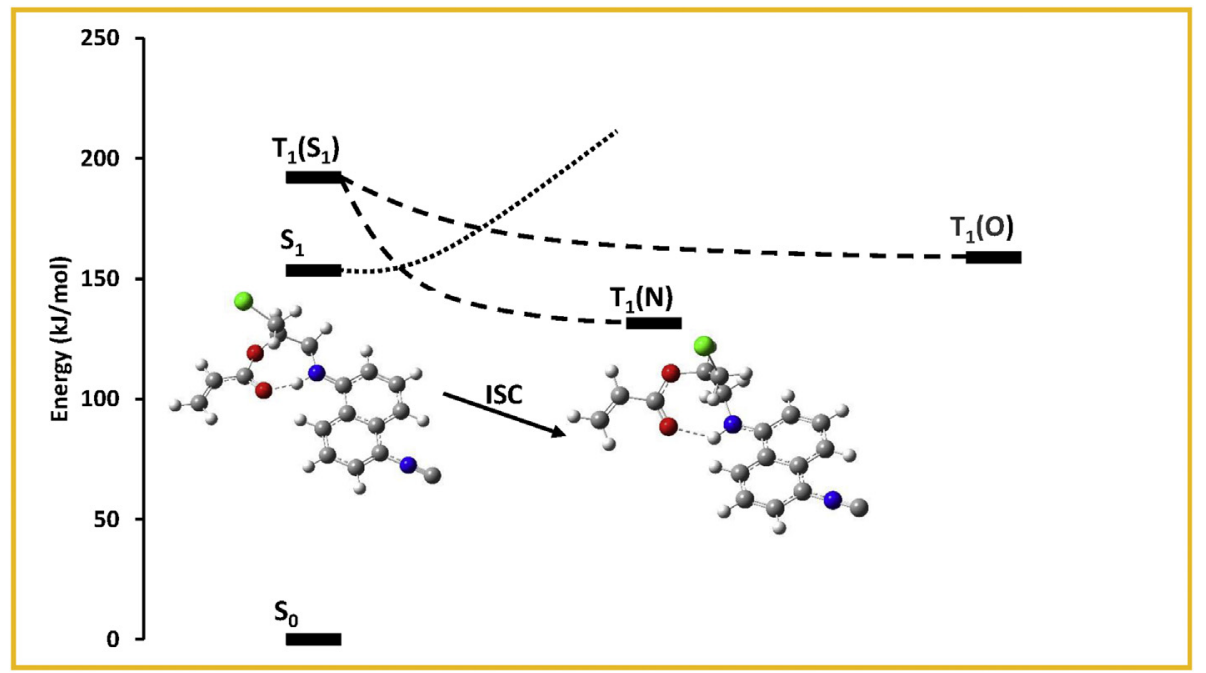

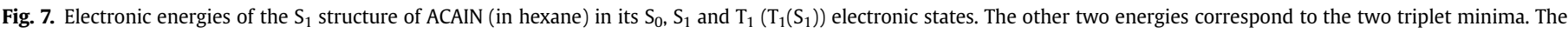
lines are approximations of the $S_{1}(\cdots)$ and $T_{1}(-)$ potential energy surfaces.

(Fig. S21), which is due to the near degenerate triplet and singlet states. It is important to note that the main emission band of the thiol adduct consists of only one transition, while the one in the calculated spectra of ACAIN has two, one at higher wavelength with very low oscillator strength and one at lower wavelength with oscillator strength similar to that of the thiol adduct. The spacing of these two transitions is larger in hexane. This result implies that the excited ACAIN molecules relax to a dark $\mathrm{S}_{1}$ state in both hexane and DMSO.

This can be explained with a LUMO "switch" during the relaxation into the $S_{1}$ geometry from the vertical excited state. There are three molecular orbitals involved in this process: the HOMO and the LUMO of the $S_{0}$ state corresponding to $\pi$ and $\pi^{*}$ orbitals of the amino-isocyanonaphthalene subunit and the $\pi^{*} \mathrm{MO}(\mathrm{LUMO}+1)$ of the acryl subunit. During the relaxation into the $S_{1}$ geometry the acryl $\pi^{*}$ MO gets lower in energy as the acryl group and the naphthalene ring becomes coplanar (in hexane) and in the equilibrium structure it is actually the LUMO (Fig. 8, note that we used HF molecular orbitals and energies because they are less diffuse compared to DFT ones therefore they reflect a more chemical picture). Because the orbital overlap between the new frontier orbitals is smaller the LUMO $\rightarrow$ HOMO transition (emission) will have a lower quantum yield. Based on this argument the overall excitation process can be viewed as an intramolecular charge transfer from the main ring to the acryl unit.

The observed emission of ACAIN is due to the "unrelaxed" molecules because the relaxation into the dark S1 state (the LUMO "switch") is a rather slow process. This explains why the emission of CHAIN and ACAIN have, in spite of a missing acryl group in the former, the same solvent dependence (Table 2) and why emission spectra do not change after addition of the thiol. In the thiol adduct the acrylic double bond gets saturated eliminating the interplay between the unoccupied orbitals of the main ring and the acryl subunit so the main emission will involve the LUMO and the HOMO

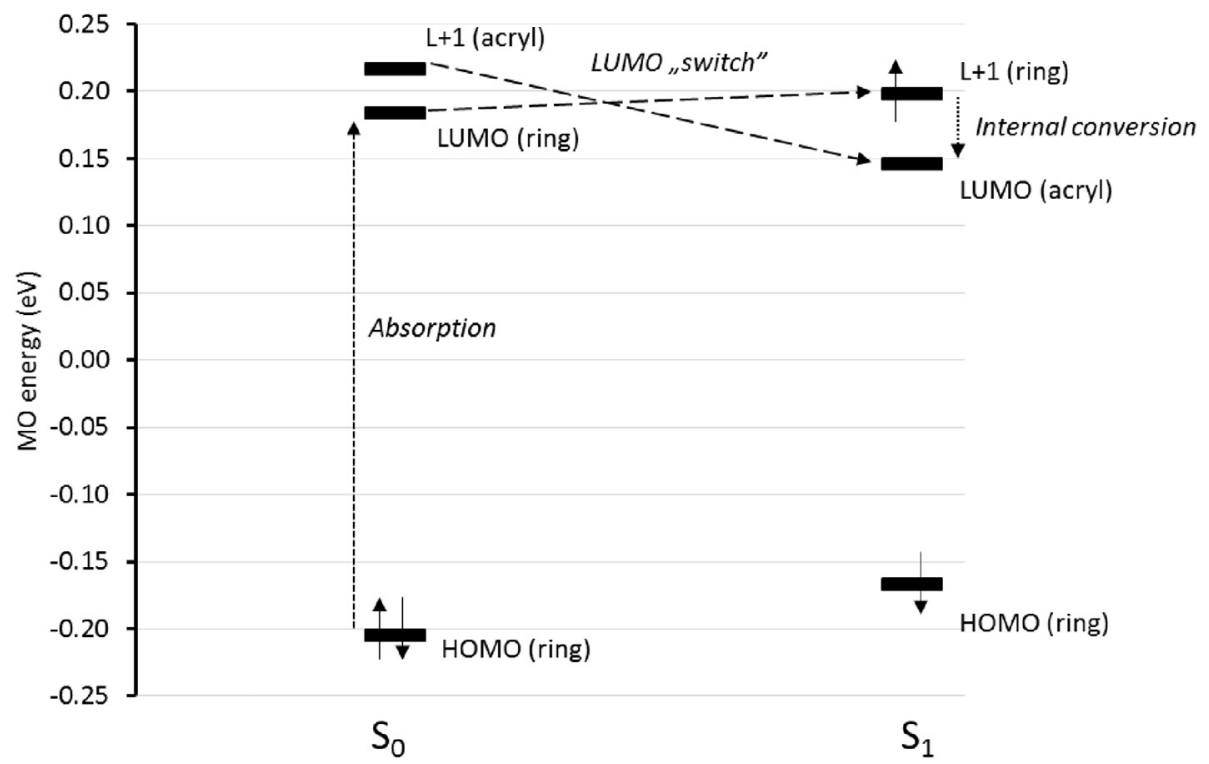

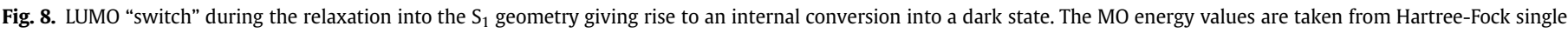
point calculations on the ground and first excited geometries calculated by DFT. 
on the amino-isocyanonaphthalene subunit which transition is fluorescent.

In order to support our model we performed calculations on molecules with modified acryl units. First the ACAIN molecule was simplified by removing the chloromethyl group (replaced by a hydrogen atom) to reduce the calculation times. This truncating has no effect on the electronic transitions investigated here therefore the chloromethyl group plays no role in the quenching of the emission observed in ACAIN. However, when an acrylic hydrogen atom is substituted with an electron-donating methyl group, it is expected to destabilize the molecular orbitals containing the acryl $\pi$-system thereby increasing the HOMO-LUMO gap. The calculations indeed show a higher energy $\mathrm{S}_{1}$ state with increased singlettriplet gap which means a less probable internal conversion. In addition, when an electron withdrawing chlorine atom is used as the substituent instead of the methyl group calculations show the opposite effect (Table S5).

After these results we performed calculations on MACAIN and found good correlation between the experimental quantum yield and the calculated singlet-triplet energy difference (Table S6).

\section{Conclusions}

1-(2-acryloyloxy-3-chloro-prop-1-yl)-amino-5isocyanonaphthalene (ACAIN), 1-(2-methacryloyloxy-3-chloroprop-1-yl)-amino-5-isocyanonaphthalene (MACAIN) and (2chloroacryloyloxy-3-chloroprop-1-yl)-amino-5-

isocyanonaphthalene (CACAIN) were prepared by introducing acryl, methacryl and chloroacryl moieties using epichlorohydrin as spacer on our previously developed solvatochromic fluorophore ICAN. All three compounds exhibited real solvatochromic behavior $\left(\Delta \lambda_{\mathrm{em}} \sim 100 \mathrm{~nm}\right)$ which could be quantitatively described by the Catalán model. Interestingly, the quantum yields were found to be rather low, especially in nonpolar solvents, decreasing in the order of $\mathrm{QY}_{\text {MACAIN }}>\mathrm{QY}_{\text {ACAIN }}>\mathrm{QY}_{\text {CACAIN. }}$ ACAIN reacts rapidly and quantitatively with simple thiols in a thiol-ene type click reaction. Using propanethiol, thiophenol, and cysteine as thiols complete disappearance of the acryl double bond was observed in $5 \mathrm{~min}$ at room temperature in DMSO without any catalyst using the thiols in a molar excess. The hydrothiolation reaction was accompanied by a significant increase in fluorescence intensity depending on the solvent used. The brightening of the addition product is due to the saturation of the acrylic group and can be applied in the fluorometric monitoring of the hydrothiolation reactions. In the case of MACAIN no such reaction could be observed, while CACAIN proved to react 100 times faster in DMSO than ACAIN. Unfortunately, the improved reactivity owing to the chloroacryl moiety drastically reduces the hydrolytic stability of CACAIN, whereas ACAIN is stable under the same conditions. The biolabeling properties of ACAIN were investigated in detail by both fluorometry and ESI mass spectrometry using cysteine, lysyl-alanyl-cysteine (KAC) and BSA as a model protein. The selectivity of the labeling was tested using KAC as a simple tripeptide containing a lysine and a cysteine moiety separated by an alanine unit. Investigating the reaction by ESI-MS/ MS method no fragment ions could be found where ACAIN labelled the lysine $\mathrm{NH}_{2}$ group, only the hydrothiolation reaction with the cysteine SH group was observed. However, when labeling BSA two series of labelled products could be identified in the ESI-MS spectrum belonging to the molecules containing one and two ACAIN molecules attached covalently. Additional attachment of ACAIN to BSA most probably occurs on the only activated lysine unit of BSA in a hydrophobic pocket as was described earlier for Acrylodan, a well-known biolabeling dye.

The optical properties of ACAIN and its SH adducts were described by high level quantum chemical calculations. The optimized structures revealed the formation of an intramolecular hydrogen bond between the $\mathrm{NH}$ and $\mathrm{C}=\mathrm{O}$ moieties. This intramolecular $\mathrm{H}$-bond gives rise to a dark nonfluorescent $\mathrm{S}_{1}$ state due to a charge transfer from the amino-isocyanonaphthalene ring to the acryl group of ACAIN which is also close to a triplet state from which the molecule can return to the ground state through nonradiative decay. When the double bond is saturated by the $\mathrm{SH}$ addition the internal conversion pathway leading to nonradiative decay ceases to exist resulting in the increase of the fluorescence quantum yields of the thiolated products. The brightening is more pronounced (15-19 fold) in nonpolar solvents where the majority of the starting ACAIN molecules is locked in the internal H-bonding position and only moderate (1.5-2 fold) in polar solvents where the solvent can break up the H-bond. Based on our DFT calculations the structure of the spacer has little effect on the electronic transitions as long as the internal $\mathrm{H}$-bond can form. The situation significantly changes when the modification is carried out on the acrylic part. When the acryl group is replaced by a methacryl group i.e. an electron-donating group is introduced on the double bond the calculations showed an increased singlet-triplet gap which means a less probable internal conversion. Indeed, after preparing and investigating the properties of MACAIN a good correlation between the experimental quantum yield and the calculated singlet-triplet energy difference was found. Also, if an electron withdrawing chlorine atom is used instead of the methyl group calculations show the tightening of the singlet-triplet gap, which could be applied in the construction of molecular switches based on ACAIN.

\section{Experimental}

\subsection{Materials}

Acetone, dichloromethane (DCM), hexane, 2-propanol (iPrOH), toluene, triethyl amine (reagent grade, Molar Chemicals, Hungary) were purified by distillation. Acetonitrile $(\mathrm{MeCN})$, tetrahydrofuran (THF), methanol (MeOH), dimethyl-sulfoxide (DMSO), pyridine (HPLC grade, VWR, Germany), chloroform, ethyl-acetate (EtOAc), cyclohexane, 1,4-dioxane (reagent grade, Reanal, Hungary), epichlorohydrin, acryloyl chloride, methacryloyl chloride, 2chloroacrylic acid, 4-N,N-dimethylaminopyridine, N,Ndicyclohexyl carbodiimide (Sigma-Aldrich, Germany) were used without further purification. Buffer solution pH 7.01 (HI 7007, Hanna Instruments) was used as received. Buffer solution $\mathrm{pH} 8.0$ and $9.0(0.1 \mathrm{M})$ were prepared by mixing $1 \mathrm{M} \mathrm{K}_{2} \mathrm{HPO}_{4}$ and $\mathrm{KH}_{2} \mathrm{PO}_{4}$ solutions ( $\mathrm{pH} 8.0$ ) or $1 \mathrm{M} \mathrm{K}_{2} \mathrm{HPO}_{4}$ and $1 \mathrm{M} \mathrm{HCl}$ solutions ( $\mathrm{pH} 9.0$ ) at appropriate ratios diluted with water and their final $\mathrm{pH}$ was adjusted under a $\mathrm{pH}$ meter.

\subsection{Synthesis}

\subsubsection{1-N-(3-chloro-2-hydroxyprop-1-yl)-amino-5-} isocyanonaphthalene (CHAIN)

A $250 \mathrm{ml}$ ACE pressure flask was charged with 1-amino-5isocyanonaphthalene $(1.00 \mathrm{~g}, 5.95 \mathrm{mmol})$ dissolved in ethanol $(100 \mathrm{ml})$ and with epichlorohydrin $(930 \mu \mathrm{l}, 11.9 \mathrm{mmol})$ and vigorously stirred with a magnetic stirrer at $90{ }^{\circ} \mathrm{C}$ for 3 days. After cooling down, the solvent was removed on a rotary evaporator. The crude product was purified on a column filled with normal-phase silica gel, using dichloromethane as eluent. Yield: 0.82 g, 53\% (light brown waxy solid).

${ }^{1} \mathrm{H}$ NMR $\left(360 \mathrm{MHz}, \mathrm{CDCl}_{3}\right) \delta=7.90(\mathrm{~d}, J=8.6 \mathrm{~Hz}, 1 \mathrm{H}), 7.59-7.42$ $(\mathrm{m}, 3 \mathrm{H}), 7.35(\mathrm{t}, J=8.0 \mathrm{~Hz}, 1 \mathrm{H}), 6.71(\mathrm{~d}, J=7.4 \mathrm{~Hz}, 1 \mathrm{H}), 4.85(\mathrm{~s}, 1 \mathrm{H})$, $4.25(\mathrm{~s}, 1 \mathrm{H}), 3.80-3.67(\mathrm{~m}, 2 \mathrm{H}), 3.57-3.46(\mathrm{~m}, 1 \mathrm{H}), 3.36(\mathrm{dd}, J=12.7$, $7.4 \mathrm{~Hz}, 1 \mathrm{H}), 2.80(\mathrm{~d}, J=4.7 \mathrm{~Hz}, 1 \mathrm{H}) \mathrm{ppm}$.

${ }^{13} \mathrm{C}$ NMR $\left(95 \mathrm{MHz}, \mathrm{CDCl}_{3}\right) \delta=162.64\left(\mathrm{C}_{\mathrm{NC}}\right), 140.52\left(\mathrm{C}_{9,10}\right), 126.70$ 
$\left(C_{5}\right), 126.46\left(C_{2}\right), 122.44\left(C_{7}\right), 121.66\left(C_{1}\right), 121.43\left(C_{6}\right), 119.94\left(C_{3}\right)$, $110.85\left(\mathrm{C}_{8}\right), 104.68\left(\mathrm{C}_{4}\right), 70.98\left(\mathrm{C}_{\mathrm{CHOH}}\right), 51.74\left(\mathrm{C}_{\mathrm{CH} 2}\right), 46.31\left(\mathrm{C}_{\mathrm{CH} 2 \mathrm{Cl}}\right)$ ppm.

ESI-TOF MS (m/z): calculated $m / z$ of $\left[\mathrm{C}_{14} \mathrm{H}_{13} \mathrm{ClN}_{2} \mathrm{O}+\mathrm{Na}\right]^{+}$adduct ion is 283.061 ; found; 283.060 .

\subsubsection{1-N-(2-acryloyloxy-3-chloroprop-1-yl)-amino-5- isocyanonaphthalene (ACAIN)}

Into a $250 \mathrm{ml}$ round-bottom flask charged with 1-N-(3-chloro2-hydroxyprop-1-yl)-amino-5-isocyanonaphthalene $\quad(1.00 \mathrm{~g}$, $3.84 \mathrm{mmol})$ and triethyl amine $(2.14 \mathrm{ml}, 15.3 \mathrm{mmol})$ dissolved in tetrahydrofuran ( $150 \mathrm{ml}$ ) acryloyl chloride $(623 \mu \mathrm{l}, 7.68 \mathrm{mmol})$ was added dropwise at $0{ }^{\circ} \mathrm{C}$, then stirred with a magnetic stirrer for $12 \mathrm{~h}$. The solvent was removed on a rotary evaporator and the crude product was purified on a column filled with normal-phase silica gel, using dichloromethane as eluent. Yield: $0.86 \mathrm{~g}$, 71\% (orange crystals).

${ }^{1} \mathrm{H}$ NMR $\left(360 \mathrm{MHz}, \mathrm{CDCl}_{3}\right) \delta=7.84(\mathrm{~d}, J=8.6 \mathrm{~Hz}, 1 \mathrm{H}), 7.64-7.46$ $(\mathrm{m}, 3 \mathrm{H}), 7.39(\mathrm{t}, J=8.0 \mathrm{~Hz}, 1 \mathrm{H}), 6.80(\mathrm{~d}, J=7.5 \mathrm{~Hz}, 1 \mathrm{H}), 6.51(\mathrm{~d}$, $J=17.3 \mathrm{~Hz}, 1 \mathrm{H}), 6.19(\mathrm{dd}, J=17.2,10.5 \mathrm{~Hz}, 1 \mathrm{H}), 5.94(\mathrm{~d}, J=10.4 \mathrm{~Hz}$, $1 \mathrm{H}), 5.53-5.43(\mathrm{~m}, 1 \mathrm{H}), 4.84(\mathrm{t}, J=5.2 \mathrm{~Hz}, 1 \mathrm{H}), 3.83(\mathrm{~d}, J=4.8 \mathrm{~Hz}$, $2 \mathrm{H}), 3.75-3.60(\mathrm{~m}, 2 \mathrm{H}) \mathrm{ppm}$.

${ }^{1} \mathrm{H}$ NMR $(360 \mathrm{MHz}, \mathrm{DMSO}) \delta=8.32(\mathrm{~d}, J=8.7 \mathrm{~Hz}, 1 \mathrm{H}), 7.83-7.72$ $(\mathrm{m}, 1 \mathrm{H}), 7.54(\mathrm{t}, J=8.1 \mathrm{~Hz}, 1 \mathrm{H}), 7.45(\mathrm{dd}, J=8.6,7.5 \mathrm{~Hz}, 1 \mathrm{H}), 7.29(\mathrm{~d}$, $J=8.3 \mathrm{~Hz}, 1 \mathrm{H}), 6.85(\mathrm{~d}, J=7.7 \mathrm{~Hz}, 1 \mathrm{H}), 6.74(\mathrm{t}, J=5.7 \mathrm{~Hz}, 1 \mathrm{H}), 6.36$ (dd, $J=17.2,1.6 \mathrm{~Hz}, 1 \mathrm{H}$ ), 6.19 (dd, $J=17.2,10.3 \mathrm{~Hz}, 1 \mathrm{H}$ ), 5.97 (dd, $J=10.3,1.6 \mathrm{~Hz}, 1 \mathrm{H}), 5.39(\mathrm{td}, J=9.7,6.0 \mathrm{~Hz}, 1 \mathrm{H}), 3.99$ (ddd, $J=17.9$, 12.0, $4.8 \mathrm{~Hz}, 2 \mathrm{H}), 3.67-3.49(\mathrm{~m}, 2 \mathrm{H}) \mathrm{ppm}$.

${ }^{13} \mathrm{C} \mathrm{NMR}\left(95 \mathrm{MHz}, \mathrm{CDCl}_{3}\right) \delta=162.93\left(\mathrm{C}_{\mathrm{NC}}\right), 161.96\left(\mathrm{C}_{\mathrm{C}}=\mathrm{O}\right), 140.15$ $\left(C_{9,10}\right), 130.04\left(C_{5}\right), 126.76\left(C_{1}\right), 125.37\left(C_{3}\right), 122.55\left(C_{\text {Acryl CH2 }}\right), 121.62$ $\left(\mathrm{C}_{\text {Acryl } \mathrm{CH}}\right), 119.79\left(\mathrm{C}_{6,7}\right), 111.00\left(\mathrm{C}_{2,8}\right), 104.65\left(\mathrm{C}_{4}\right), 71.67\left(\mathrm{C}_{\mathrm{CHO}}\right), 46.52$ $\left(\mathrm{C}_{\mathrm{CH} 2}\right), 45.14\left(\mathrm{C}_{\mathrm{CH} 2 \mathrm{Cl}}\right) \mathrm{ppm}$.

ESI-TOF MS $(\mathrm{m} / z)$ : calculated $\mathrm{m} / z$ of $\left[\mathrm{C}_{17} \mathrm{H}_{15} \mathrm{ClN}_{2} \mathrm{O}_{2}+\mathrm{Na}\right]^{+}$ adduct ion is 337.071; found; 337.070 .

\subsubsection{Thiol adducts of 1-N-(2-acryloyloxy-3-chloroprop-1-yl)- amino-5-isocyanonaphthalene (ACAIN)}

A $25 \mathrm{ml}$ round-bottom flask was charged with $1-\mathrm{N}-(2-$ acryloyloxy-3-chloroprop-1-yl)-amino-5-isocyanonaphthalene $(0.050 \mathrm{~g}, 0.16 \mathrm{mmol})$, the thiol $(0.16 \mathrm{mmol})$ dissolved in $5 \mathrm{ml}$ DMSO and was stirred with a magnetic stirrer for $10 \mathrm{~min}$ to $6 \mathrm{~h}$ at room temperature, then extracted with water and dichloromethane. The organic phase was separated, dried on anhydrous magnesium sulfate, and the solvent was removed on a rotary evaporator. Yield: $46-95 \%$.

4.2.3.1. Adduct formed with 1-propanethiol. ${ }^{1} \mathrm{H}$ NMR $(360 \mathrm{MHz}$, $\left.\mathrm{CDCl}_{3}\right) \delta=7.89(\mathrm{~d}, J=8.6 \mathrm{~Hz}, 1 \mathrm{H}), 7.56(\mathrm{dt}, J=16.0,8.4 \mathrm{~Hz}, 3 \mathrm{H}), 7.38$ $(\mathrm{t}, J=8.0 \mathrm{~Hz}, 1 \mathrm{H}), 6.78(\mathrm{~d}, J=7.5 \mathrm{~Hz}, 1 \mathrm{H}), 5.45(\mathrm{dq}, J=9.8,4.9 \mathrm{~Hz}$, $1 \mathrm{H}), 4.86(\mathrm{~s}, 1 \mathrm{H}), 3.80(\mathrm{~d}, J=5.1 \mathrm{~Hz}, 2 \mathrm{H}), 3.72-3.58(\mathrm{~m}, 2 \mathrm{H})$, 2.86-2.75 (m, 2H), 2.73-2.70 (m, 1H), $2.48(\mathrm{t}, J=7.3 \mathrm{~Hz}, 2 \mathrm{H})$, $1.63-1.50(\mathrm{~m}, 3 \mathrm{H}), 0.94(\mathrm{t}, J=7.3 \mathrm{~Hz}, 3 \mathrm{H}) \mathrm{ppm}$.

ESI-TOF MS $(m / z)$ : calculated $m / z$ of $\left[\mathrm{C}_{20} \mathrm{H}_{23} \mathrm{ClN}_{2} \mathrm{OS}+\mathrm{Na}\right]^{+}$ adduct ion is 413.106; found; 413.106 .

4.2.3.2. Adduct formed with thiophenol. ${ }^{1} \mathrm{H}$ NMR (360 MHz, DMSO) $\delta=8.33(\mathrm{~d}, J=8.7 \mathrm{~Hz}, 1 \mathrm{H}), 7.75(\mathrm{~d}, J=7.1 \mathrm{~Hz}, 1 \mathrm{H}), 7.53(\mathrm{t}, J=8.1 \mathrm{~Hz}$, $1 \mathrm{H}), 7.44(\mathrm{dd}, J=8.5,7.5 \mathrm{~Hz}, 1 \mathrm{H}), 7.37-7.16(\mathrm{~m}, 4 \mathrm{H}), 7.11(\mathrm{t}$, $J=7.2 \mathrm{~Hz}, 1 \mathrm{H}), 6.83(\mathrm{~d}, J=7.8 \mathrm{~Hz}, 1 \mathrm{H}), 6.70(\mathrm{t}, J=5.8 \mathrm{~Hz}, 1 \mathrm{H})$, $5.39-5.31(\mathrm{~m}, 2 \mathrm{H}), 3.94(\mathrm{qd}, J=11.9,4.8 \mathrm{~Hz}, 2 \mathrm{H}), 3.62-3.46(\mathrm{~m}, 2 \mathrm{H})$, $3.12(\mathrm{t}, J=7.0 \mathrm{~Hz}, 2 \mathrm{H}), 2.63(\mathrm{t}, J=7.0 \mathrm{~Hz}, 2 \mathrm{H}) \mathrm{ppm}$.

ESI-TOF MS $(m / z)$ : calculated $m / z$ of $\left[\mathrm{C}_{23} \mathrm{H}_{21} \mathrm{ClN}_{2} \mathrm{O}_{2} \mathrm{~S}+\mathrm{K}\right]^{+}$ adduct ion is 463.064; found; 463.064 .

4.2.3.3. Adduct formed with cysteine. ${ }^{1} \mathrm{H}$ NMR (360 MHz, DMSO) $\delta=13.95(\mathrm{~s}, 1 \mathrm{H}), 8.23(\mathrm{~d}, J=8.6 \mathrm{~Hz}, 1 \mathrm{H}), 7.72(\mathrm{~d}, J=7.3 \mathrm{~Hz}, 1 \mathrm{H}), 7.54$ $(\mathrm{t}, J=8.1 \mathrm{~Hz}, 1 \mathrm{H}), 7.44(\mathrm{t}, J=8.0 \mathrm{~Hz}, 1 \mathrm{H}), 7.27(\mathrm{~d}, J=8.3 \mathrm{~Hz}, 1 \mathrm{H}), 6.80$ $(\mathrm{d}, J=7.8 \mathrm{~Hz}, 1 \mathrm{H}), 5.28$ (d, $J=4.6 \mathrm{~Hz}, 1 \mathrm{H}), 3.89-3.77$ (m, 2H), 3.52 (ddd, $J=21.3,14.4,6.2 \mathrm{~Hz}, 2 \mathrm{H}$ ), 3.41 (s, 2H), 2.96 (dd, $J=14.2,3.5 \mathrm{~Hz}$, $1 \mathrm{H}), 2.86-2.70(\mathrm{~m}, 3 \mathrm{H}), 2.66(\mathrm{~s}, 2 \mathrm{H}), 2.63-2.54(\mathrm{~m}, 2 \mathrm{H}) \mathrm{ppm}$.

ESI-TOF MS $(\mathrm{m} / \mathrm{z})$ : calculated $m / z$ of $\left[\mathrm{C}_{20} \mathrm{H}_{22} \mathrm{ClN}_{3} \mathrm{O}_{4} \mathrm{~S}+\mathrm{Na}\right]^{+}$ adduct ion is 458.091; found; 458.091 .

4.2.3.4. Adduct formed with 1-thio-2,3,4,6-tetra-O-acetyl- $\beta$-dglucose. ${ }^{1} \mathrm{H}$ NMR $\left(400 \mathrm{MHz}, \mathrm{CDCl}_{3}\right) \delta=7.91(\mathrm{dd}, J=8.5,2.6 \mathrm{~Hz}, 1 \mathrm{H})$, $7.62-7.50(\mathrm{~m}, 3 \mathrm{H}), 7.47-7.37(\mathrm{~m}, 1 \mathrm{H}), 6.78(\mathrm{~d}, J=7.5 \mathrm{~Hz}, 1 \mathrm{H})$, $5.49-5.40(\mathrm{~m}, 1 \mathrm{H}), 5.19(\mathrm{tt}, J=9.6,4.8 \mathrm{~Hz}, 1 \mathrm{H}), 5.10-5.01(\mathrm{~m}, 1 \mathrm{H})$, $5.01-4.91(\mathrm{~m}, 1 \mathrm{H}), 4.48(\mathrm{dd}, J=10.0,6.4 \mathrm{~Hz}, 1 \mathrm{H}), 4.19-4.06(\mathrm{~m}, 3 \mathrm{H})$, $3.80(\mathrm{~d}, J=4.9 \mathrm{~Hz}, 2 \mathrm{H}), 3.71-3.57(\mathrm{~m}, 3 \mathrm{H}), 3.02(\mathrm{tt}, J=11.1,7.1 \mathrm{~Hz}$, $1 \mathrm{H}), 2.90(\mathrm{td}, J=13.7,7.1 \mathrm{~Hz}, 1 \mathrm{H}), 2.77(\mathrm{dt}, J=7.3,3.6 \mathrm{~Hz}, 2 \mathrm{H})$, 2.07-1.98 (m, 12H) ppm.

ESI-TOF MS $(m / z)$ : calculated $m / z$ of $\left[\mathrm{C}_{31} \mathrm{H}_{35} \mathrm{ClN}_{2} \mathrm{O}_{11} \mathrm{~S}+\mathrm{Na}\right]^{+}$ adduct ion is 701.154; found; 701.154 .

\subsubsection{1-N-(2-methacryloyloxy-3-chloroprop-1-yl)-amino-5- isocyanonaphthalene (MACAIN)}

Into a $250 \mathrm{ml}$ round-bottom flask charged with 1-N-(3-chloro2-hydroxyprop-1-yl)-amino-5-isocyanonaphthalene $\quad(1.00 \mathrm{~g}$, $3.84 \mathrm{mmol})$ and triethyl amine $(2.14 \mathrm{ml}, 15.3 \mathrm{mmol})$ dissolved in tetrahydrofuran $(150 \mathrm{ml})$ methacryloyl chloride $(740 \mu \mathrm{l}, 7.68 \mathrm{mmol})$ was added dropwise at $0{ }^{\circ} \mathrm{C}$, then stirred with a magnetic stirrer for $12 \mathrm{~h}$. The solvent was removed on a rotary evaporator and the crude product was purified on a column filled with normal-phase silica gel, using dichloromethane as eluent. Yield: $0.28 \mathrm{~g}, 22 \%$ (orange crystals).

${ }^{1} \mathrm{H}$ NMR $\left(360 \mathrm{MHz}, \mathrm{CDCl}_{3}\right) \delta=7.83(\mathrm{~d}, J=8.6 \mathrm{~Hz}, 1 \mathrm{H}), 7.62-7.48$ $(\mathrm{m}, 3 \mathrm{H}), 7.39(\mathrm{t}, J=7.9 \mathrm{~Hz}, 1 \mathrm{H}), 6.81(\mathrm{~d}, J=7.4 \mathrm{~Hz}, 1 \mathrm{H}), 6.21(\mathrm{~s}, 1 \mathrm{H})$, $5.67(\mathrm{t}, J=1.4 \mathrm{~Hz}, 1 \mathrm{H}), 5.39-5.51(\mathrm{~s}, 1 \mathrm{H}), 4.86(\mathrm{~s}, 1 \mathrm{H}), 3.84(\mathrm{~d}$, $J=4.8 \mathrm{~Hz}, 2 \mathrm{H}), 3.60-3.74(\mathrm{~m}, 2 \mathrm{H}), 1.98(\mathrm{~s}, 3 \mathrm{H})$. ppm.

${ }^{13} \mathrm{C}$ NMR $\left(95 \mathrm{MHz}, \mathrm{CDCl}_{3}\right) \delta={ }^{13} \mathrm{C}$ NMR $\left(91 \mathrm{MHz}, \mathrm{CDCl}_{3}\right) \delta 167.17$ $\left(C_{N C}, C_{C}=0\right), 143.23\left(C_{9,10}\right), 135.69\left(C_{5}\right), 129.20\left(C_{1}\right), 128.92\left(C_{3}\right)$, 127.05 ( $\left.\mathrm{C}_{\text {Methacryl CH2 }}\right), 124.69\left(\mathrm{C}_{7}\right), 123.84$ ( $\left.\mathrm{C}_{\text {Methacryl }}\right), 123.74\left(\mathrm{C}_{6}\right)$, $121.79\left(\mathrm{C}_{8}\right), 112.67\left(\mathrm{C}_{2}\right), 106.00\left(\mathrm{C}_{4}\right), 71.76\left(\mathrm{C}_{\mathrm{CHO}}\right), 45.34\left(\mathrm{C}_{\mathrm{CH} 2}\right), 43.87$ $\left(\mathrm{C}_{\mathrm{CH} 2 \mathrm{Cl}}\right), 18.25\left(\mathrm{C}_{\text {Methacryl CH3 }}\right)$.

ESI-TOF MS $(m / z)$ : calculated $m / z$ of $\left[\mathrm{C}_{18} \mathrm{H}_{17} \mathrm{ClN}_{2} \mathrm{O}_{2}+\mathrm{Na}\right]^{+}$ adduct ion is 351.087; found; 351.087 .

\subsubsection{1-N-(2-chloroacryloyloxy-3-chloroprop-1-yl)-amino-5-}

isocyanonaphthalene (CACAIN)

Into a $50 \mathrm{ml}$ round-bottom flask charged with $1-\mathrm{N}-(3-$ chloro-2hydroxyprop-1-yl)-amino-5-isocyanonaphthalene $(500 \mathrm{mg}$, $1.92 \mathrm{mmol}), 4-\mathrm{N}, \mathrm{N}-$ dimethylaminopyridine $(26.0 \mathrm{mg}, 0.210 \mathrm{mmol})$ and 2-chloroacrylic acid (225 $\mathrm{mg}, 2.11 \mathrm{mmol}$ ) dissolved in dichloromethane $(15 \mathrm{ml}) \mathrm{N}, \mathrm{N}$-dicyclohexyl carbodiimide $(435 \mathrm{mg}$, $2.11 \mathrm{mmol}$ ) dissolved in dichloromethane $(5 \mathrm{ml})$ was added dropwise at $0{ }^{\circ} \mathrm{C}$, then stirred with a magnetic stirrer for 2 days. The solvent was removed on a rotary evaporator and the crude product was purified on a column filled with normal-phase silica gel, using dichloromethane as eluent. Yield: $0.33 \mathrm{~g}, 49 \%$ (pale yellow viscous oil).

${ }^{1} \mathrm{H}$ NMR $\left(360 \mathrm{MHz}, \mathrm{CDCl}_{3}\right) \delta=7.84(\mathrm{~d}, J=8.6 \mathrm{~Hz}, 1 \mathrm{H}), 7.65-7.46$ (m, 3H), $7.41(\mathrm{dd}, J=8.6,7.4 \mathrm{~Hz}, 1 \mathrm{H}), 6.83(\mathrm{~d}, J=7.5 \mathrm{~Hz}, 1 \mathrm{H}), 6.59$ (d, $J=10.3 \mathrm{~Hz}, 1 \mathrm{H}), 6.09(\mathrm{~d}, J=10.2 \mathrm{~Hz}, 1 \mathrm{H}), 5.52-5.40(\mathrm{~m}, 1 \mathrm{H}), 4.77(\mathrm{~s}$, $1 \mathrm{H}), 3.86(\mathrm{~d}, J=4.8 \mathrm{~Hz}, 2 \mathrm{H}), 3.73(\mathrm{t}, J=5.8 \mathrm{~Hz}, 2 \mathrm{H}) \mathrm{ppm}$.

${ }^{13} \mathrm{C} \mathrm{NMR}\left(91 \mathrm{MHz}, \mathrm{CDCl}_{3}\right) \delta=167.15\left(\mathrm{C}_{\mathrm{C}}=\mathrm{O}\right), 161.75\left(\mathrm{C}_{\mathrm{NC}}\right), 142.91$ $\left(\mathrm{C}_{9,10}\right), 130.80\left(\mathrm{C}_{5}\right), 129.19\left(\mathrm{C}_{1}\right), 128.88\left(\mathrm{C}_{\text {Chloroacryl }} \mathrm{CH}_{2}\right), 127.29$ $\left(C_{\text {Chloroacryl }} \mathrm{CH}\right), 126.61\left(\mathrm{C}_{3}\right), 124.80\left(\mathrm{C}_{7}\right), 123.92\left(\mathrm{C}_{6}\right), 121.73\left(\mathrm{C}_{8}\right)$, $113.01\left(\mathrm{C}_{2}\right), 106.15\left(\mathrm{C}_{4}\right), 73.56\left(\mathrm{C}_{\mathrm{CHO}}\right), 44.87\left(\mathrm{C}_{\mathrm{CH} 2}\right), 43.38\left(\mathrm{C}_{\mathrm{CH} 2 \mathrm{Cl}}\right)$ ppm.

ESI-TOF MS $(m / z)$ : calculated $m / z$ of $\left[\mathrm{C}_{17} \mathrm{H}_{14} \mathrm{Cl}_{2} \mathrm{~N}_{2} \mathrm{O}_{2}-\mathrm{H}\right]^{-}$ion is 
346.036; found; 346.036 .

\subsubsection{Lysyl-alanyl-cysteine (KAC)}

The KAC tripeptide with terminal amino and amide functionalities (see Fig. 2) was synthesized by solid phase peptide synthesis using a microwave-assisted Liberty 1 Peptide Synthesizer (CEM, Matthews, NC). Fmoc-protected amino acid derivatives were introduced according to the Fmoc/tBu technique and the TBTU/ HOBt/DIEA strategy. Cleaving on the $\alpha$-amino protecting group of amino acids and resin was performed by 30 Watts microwave power for $180 \mathrm{~s}$ at $80^{\circ} \mathrm{C}$ using $20 \mathrm{~V} / \mathrm{V} \%$ piperidine and $0.1 \mathrm{M} \mathrm{HOBt} \cdot \mathrm{H}_{2} \mathrm{O}$ in DMF. Four times excess of amino acids and 30 Watts microwave power for $300 \mathrm{~s}$ was used for coupling at $80^{\circ} \mathrm{C}$ in the presence of $0.5 \mathrm{M}$ HOBt and 0.5 M TBTU in DMF as activator and $2 \mathrm{M}$ DIPEA in NMP as activator base. After building up the peptide sequences, Fmoc group was removed similarly while the side chain protecting groups were cleaved with the treatment of TFA/TIS $/ \mathrm{H}_{2} \mathrm{O} / 2,2^{\prime}$-(ethylenedioxy)diethanethiol $(94 / 2.5 / 2.5 / 1 \mathrm{~V} / \mathrm{V})$ mixture, simultaneously with the removal of the peptide from the resin, at room temperature for $2 \mathrm{~h}$. The resin was filtered from the trifluoracetic acid solution of the peptide which was precipitated in cold diethyl ether. The crude product was also washed using this solvent and dried after separation followed by dissolution in water and freezing for lyophilization.

The purity of the prepared products was checked by analytical rp-HPLC using a Jasco instrument equipped with a Jasco MD-2010 plus multiwavelength detector monitoring the absorbance at $222 \mathrm{~nm}$.

Gradient elution was carried out using solvent $A(0.1 \mathrm{~V} / \mathrm{V} \% \mathrm{TFA}$ in acetonitrile) and solvent $B(0.1 \mathrm{~V} / \mathrm{V} \%$ TFA in water $)$ at a flow rate of $0.8 \mathrm{ml} / \mathrm{min}$. From $1 \mathrm{~min}$ to $15 \mathrm{~min} 0-25 \%$ of $\mathrm{A}$, from $15 \mathrm{~min}$ to $16 \mathrm{~min} 25 \%$ of $\mathrm{A}$ and from $16 \mathrm{~min}$ to $20 \mathrm{~min} 25$ to $0 \%$ of $A$ was applied and a Teknokroma Europa Peptide C18 chromatographic column $(250 \times 4.6 \mathrm{~mm}, 120 \AA$ pore size, $5 \mu \mathrm{m}$ particle size $)$ was used.

Chemicals and solvents used for synthetic purpose were purchased from commercial sources in the highest available purity and used without further purification. Rink Amide AM resin, 2-(1-Hbenzotriazole-1-yl)-1,1,3,3-tetramethyluronium tetrafluoroborate (TBTU) and all N-fluorenylmethyloxycarbonyl (Fmoc)-protected amino acids (Fmoc-Cys(Trt)-OH, Fmoc-Lys(Boc)-OH and Fmoc-Ala$\mathrm{OH}$ ) are Novabiochem (Switzerland) products. 2-methyl-2-butanol, $\mathrm{N}$-hydroxybenzotriazole (HOBt), N-methyl-pyrrolidone (NMP), 2,2'-(ethylenedioxy)diethanethiol (DODT) and triisopropylsilane (TIS) were purchased from Sigma-Aldrich Co., while N,Ndiisopropyl-ethylamine (DIEA) and trifluoroacetic acid (TFA) were Merck Millipore Co. products. Peptide-synthesis grade $\mathrm{N}, \mathrm{N}-$ dimethylformamide (DMF) and acetic anhydride $\left(\mathrm{Ac}_{2} \mathrm{O}\right)$ were from VWR International and piperidine, dichloromethane (DCM), diethyl ether $\left(\mathrm{Et}_{2} \mathrm{O}\right)$, acetic acid $(\mathrm{AcOH})$ and acetonitrile $(\mathrm{ACN})$ were from Molar Chemicals Ltd.

\section{Methods}

\section{1. $N M R$}

${ }^{1} \mathrm{H}$ and ${ }^{13} \mathrm{C}$ NMR spectra were recorded in $\mathrm{CDCl}_{3}$ and DMSO- $d_{6}$ at $25{ }^{\circ} \mathrm{C}$ on a Bruker Avance DRX-400 and a Bruker AM 360 spectrometer at $400 \mathrm{MHz}$ and $360 \mathrm{MHz}$, respectively with tetramethylsilane as the internal standard.

\subsection{Electrospray quadrupole time-of-flight MS/MS (ESI-Q-TOF)}

The MS and MS/MS measurements were carried out by a MicroTOF-Q type Qq-TOF MS instrument (Bruker Daltonik, Bremen,
Germany). The instrument was equipped with an electrospray ion source where the spray voltage was $4 \mathrm{kV}$. $\mathrm{N}_{2}$ was utilized as drying gas. The temperature of the drying gas was $200^{\circ} \mathrm{C}$ and the flow rate was $4.0 \mathrm{~L} / \mathrm{min}$. For the tandem MS measurements collision gas was nitrogen. The precursor ions for MS/MS were selected with an isolation width of $4 \mathrm{~m} / z$ units. The mass spectra were recorded by means of a digitizer at a sampling rate of $2 \mathrm{GHz}$. The mass spectra were calibrated externally using the exact masses of cluster ions of sodium trifluoracetate $\left[(\mathrm{NaTFA})_{\mathrm{n}}+\mathrm{Na}\right]^{+}$generated under electrospray condition. In the case of the BSA and BSA derivatives the collision RF of the quadrupole analyzer was set to 700 . The spectra were evaluated with the DataAnalysis 3.4 software from Bruker. The samples were introduced by a syringe pump (Cole-Parmer Ins. Co., Vernon Hills, IL, USA) at a flow rate of $10 \mu \mathrm{l} / \mathrm{min}$. For the mass spectrometric measurements the samples were dissolved in methanol in the concentration of $0.1 \mathrm{mM}$. In order to generate the protonated adduct ions in the case of the BSA and BSA derivatives samples low amount of formic acid was added $\left(c_{\text {acid }}=0.01 \mathrm{M}\right)$.

\section{3. $U V-V i s$}

The UV-Vis spectra were recorded on an Agilent Cary 60 spectrophotometer (Agilent, Santa Clara, CA, USA) in a quartz cuvette of $1.00 \mathrm{~cm}$ optical length. $3.00 \mathrm{~cm}^{3}$ solution was prepared from the sample.

\subsection{Fluorescence measurements}

Steady-state fluorescence measurements were carried out using a Jasco FP-8200 fluorescence spectrophotometer equipped with a Xe lamp light source. The excitation and emission spectra were recorded at $20{ }^{\circ} \mathrm{C}$, using $2.5 \mathrm{~nm}$ excitation, $5.0 \mathrm{~nm}$ emission bandwidth, and $200 \mathrm{~nm} / \mathrm{min}$ scanning speed. Fluorescence quantum yields were calculated by using quinine-sulfate in $0.1 \mathrm{~mol} / \mathrm{L}$ sulfuric acid as the reference absolute quantum efficiency $\left(\Phi_{\mathrm{n}}=55 \%\right)$.

For UV-Vis and fluorescence measurements the investigated compounds were dissolved in acetonitrile at a concentration of $1.19 \mathrm{mM}$ and was diluted to $2.38 \times 10^{-5} \mathrm{M}$ and $4.76 \times 10^{-6} \mathrm{M}$ in the solvents in interest. The spectra were processed using Spekwin32 software [34].

\subsection{Density functional theory (DFT) calculations}

All calculations were performed using the Gaussian09 C.01 software package [35]. We employed DFT and TDDFT for geometry optimizations at the ground and excited states respectively. The chosen functional was the M06 [36] with the TZVP basis set [37] because it is able to describe some amount of the dispersion forces in contrast to B3LYP [38] and CAM-B3LYP [39] which was found to be necessary to properly optimize $\pi$-stacked structures [33]. The calculations were done using the IEF-PCM solvent model [40-43].

\section{Acknowledgment}

This work was financially supported by the grant K-116465 given by OTKA (National Found for Scientific Research Development, Hungary). This paper was supported by a János Bolyai Research Scholarship of the Hungarian Academy of Sciences (M. N.). This work was partially supported by the European Union and the European Social Fund through project Supercomputer, the National Virtual Lab, grant no.: TÁMOP-4.2.2.C-11/1/KONV-2012-0010. The authors also would like to express their thanks to Ms. Katalin Várnagy for providing the KAC tripeptide sample. 


\section{Appendix A. Supplementary data}

Supplementary data related to this article can be found at http:// dx.doi.org/10.1016/j.dyepig.2016.06.036.

\section{References}

[1] Nair DP, Podgórski M, Chatani S, Gong T, Xi W, Fenoli CR, et al. Chem Mater 2014;26:724-44.

[2] Kolb HC, Finn MG, Sharpless KB. Angew Chem Int Ed 2001;40:2004-21.

[3] Baskin JM, Bertozzi CR. OSAR Comb Sci 2007:26:1211-9.

[4] Nwe K, Brechbiel MW. Cancer Biother Radio 2009;24:289-302.

[5] Wang SQ, Wu QH, Wang HY, Zheng XX, Shen SL, Zhang YR, et al. Biosens Bioelectron 2014:55:386-90.

[6] Hoyle CE, Lowe AB, Bowman CN. Chem Soc Rev 2010;39:1355-87.

[7] Li GZ, Randev RK, Soeriyadi AH, Rees G, Boyer C, Tong Z, et al. Polym Chem 2010;1:1196-204.

[8] Matsumoto T, Urano Y, Shoda T, Kojima H, Nagano T. Org Lett 2007:9:3375-7.

[9] Lin W, Yuan L, Cao Z, Feng Y, Long L. Chem Eur J 2009;15:5096-103.

[10] Sun YQ, Chen M, Liu J, Lv X, Li JF, Guo W. Chem Commun 2011;47:11029-31.

[11] Lallana E, Sousa-Herves A, Fernandez-Trillo F, Riguera R, Fernandez-Megia E. Pharm Res 2012;29:1-34.

[12] Lowe AB. Polym Chem 2010;1:17-36.

[13] Jones MW, Gibson MI, Mantovani G, Haddleton DM. Polym Chem 2011;2: $572-4$

[14] Loving GS, Sainlos M, Imperiali B. Trends Biotechnol 2009;28:73-83.

[15] Sommer A, Gorges R, Kostner GM, Paltauf F, Hermetter A. Biochemistry 1991:30:11245-9.

[16] Mims MP, Sturgis CB, Sparrow JT, Morrisett JD. Biochemistry 1993;32: 9215-20.

[17] Flora K, Brennan JD, Baker GA, Doody MA, Bright FV. Biophys J 1998;75 1084-96.

[18] Baudier J, Glasser N, Duportail G. Biochemistry 1986;25:6934-41.

[19] Oztug Durer ZA, Kudryashov DS, Sawaya MR, Altenbach C, Hubbell W,
Reisler E. Biophys J 2012;103:930-9.

[20] Simard JR, Getlik M, Grütter C, Pawar V, Wulfert S, Rabiller M, et al. J Am Chem Soc 2009;131:13286-96.

[21] Bottari G, Leigh DA, Perez EM. J Am Chem Soc 2003;125:13360-1.

[22] Lewis PA, Inman CE, Maya F, Tour JM, Hutchison JE, Weiss PS. J Am Chem Soc 2005; $127: 17421-6$

[23] Saha S, Stoddart JF. Chem Soc Rev 2007;36:77-92.

[24] Olofsson J, Önfelt B, Lincoln P. J Phys Chem A 2004;108:4391-8.

[25] Rácz D, Nagy M, Mándi A, Zsuga M, Kéki S. J Photoch Photobio A 2013;270: 19-27.

[26] Szajewski RP, Whitesides GM. J Am Chem Soc 1980;102:2011-66.

[27] Wilson JM, Wu D, Motiu-DeGrood R, Hupe DJ. J Am Chem Soc 1980;102: 359-63.

[28] Pedersen AO, Jacobsen J. Eur J Biochem 1980;106:291-5.

[29] Noble DR, Williams DLH. J Chem Soc Perkin Trans 2001;2:13-7.

[30] Yem AW, Epps DE, Mathews WR, Guido DM, Richard KA, Staite ND, et al. J Biol Chem 1992;267:3122-8.

[31] Brown JR. Fed Proc Fed Am Soc Exp Biol 1975;34:591.

[32] Hirayama K, Akashi S, Furuya M, Fukuhara K. Biochem Biophys Res Commun 1990;173:639-46.

[33] Nagy M, Rácz D, Lázár L, Purgel M, Ditrói T, Zsuga M, et al. ChemPhysChem 2014; $15: 3614-25$.

[34] Menges F. Spekwin32-optical spectroscopy software. Version 1.72.0. 2015 http://www.efemm2.de/spekwin.

[35] Frisch MJ, Trucks GW, Schlegel HB, Scuseria GE, Robb MA, Cheeseman JR. Gaussian 09, revision A.02. Wallingford CT: Gaussian, Inc; 2009.

[36] Zhao Y, Truhlar DG. Theor Chem Acc 2008;120:215-41.

[37] Schaefer A, Huber C, Ahlrichs RJ. Chem Phys 1994;100:5829-35.

[38] Becke AD. J Chem Phys 1993;98:1372-7.

[39] Yanai T, Tew D, Handy N. Chem Phys Lett 2004;393:51-7.

[40] Tomasi J, Mennucci B, Cammi R. Chem Rev 2005;105:2999-3093.

[41] Scalmani G, Frisch MJ. J Chem Phys 2010;11. 114-110.

[42] Tomasi J, Mennucci B, Cances E. Theochem 1999;464:211.

[43] Pascual-Ahuir JL, Silla E, Tunon I. J Comput Chem 1994;15:1127-38.

[44] Catalán J. J Phys Chem B 2009;113:5951-60. 